\title{
A multi-objective optimisation approach applied to offshore wind farm location selection
}

\author{
V. Mytilinou ${ }^{1}$ - A. J. Kolios ${ }^{1}$ (1)
}

Received: 2 February 2017 / Accepted: 6 July 2017 / Published online: 26 July 2017

(C) The Author(s) 2017. This article is an open access publication

\begin{abstract}
This paper compares the three state-of-the-art algorithms when applied to a real-world case of the wind energy sector. Optimum locations are suggested for a wind farm by considering only Round 3 zones around the UK. The problem comprises of some of the most important technoeconomic life cycle cost-related factors, which are modelled using the physical aspects of each wind farm location (i.e., the wind speed, distance from the ports, and water depth), the wind turbine size, and the number of turbines. The model is linked to NSGA II, NSGA III, and SPEA 2 algorithms, to conduct an optimisation search. The performance of these three algorithms is demonstrated and analysed, so as to assess their effectiveness in the investment decision-making process in the wind sector, more importantly, for Round 3 zones. The results are subject to the specifics of the underlying life cycle cost model.
\end{abstract}

Keywords Round 3 - Multi-objective optimisation - UK · NSGAII $\cdot$ III $\cdot$ SPEA $2 \cdot$ Decision-making

\section{Introduction}

In the last few decades, a necessity to reduce carbon emissions has been raised after concerns of the global warming effect that causes rapid changes in the environment. In fact, electricity production was found to be responsible for at least $24 \%$ of the total greenhouse emitted gases, in 2013 (Lin and Chen 2013). The awareness around the environmental impact

$\triangle$ A. J. Kolios

a.kolios@cranfield.ac.uk

1 Renewable Energy Marine Structures Centre for Doctoral Training, Cranfield University, Cranfield, Bedfordshire MK43 0AL, UK led to further alternative ways to generate energy for more sustainable solutions. According to the 20-20-20 target on reducing carbon emissions and the new Climate Conference in Paris (COP 21) on keeping the global warming temperature below $2{ }^{\circ} \mathrm{C}$, it is important to contribute to the renewable energy (RE) investment growth in the UK by making the investments more attractive, information-rich and less risky (BEC CREW 2015).

Wind energy is one of the fastest growing forms of $\mathrm{RE}$ in the UK; however, since structural material prices have significantly increased over the last years, it has a direct impact on larger scale wind projects, the overall cost of turbines, and their operational and maintenance costs (European Observation 2011; Lin and Chen 2013; Mytilinou et al. 2015). The UK technology roadmap highlights that the offshore wind costs need to be reduced to $£ 100$ per MWh by 2020 and a greater confidence over financial motivations is required (Department of Energy and Climate Change 2011). The location of a wind farm and the type of support structure have great impacts on the installation costs. The most important costs in an offshore wind farm can be found in HM Government (2013).

The Crown Estate released Round 3 leases and provided 9 new considerably larger zones than Rounds 1 and 2; offshore wind farm zones will include up to $32 \mathrm{GW}$ of power capacity. The new leases encourage larger scale investment plans and bigger wind turbines. The new zones include locations further away from the shore and deeper waters which could be more challenging (Department of Energy and Climate Change 2011; Renewables First 2017; The Crown Estate 2010a,b, 2013).

Decision making for offshore wind energy investment is governed by a variety of criteria as can be found in (Kolios et al. 2010, 2014, 2016; Lozano-Minguez et al. 2011; Mar- 


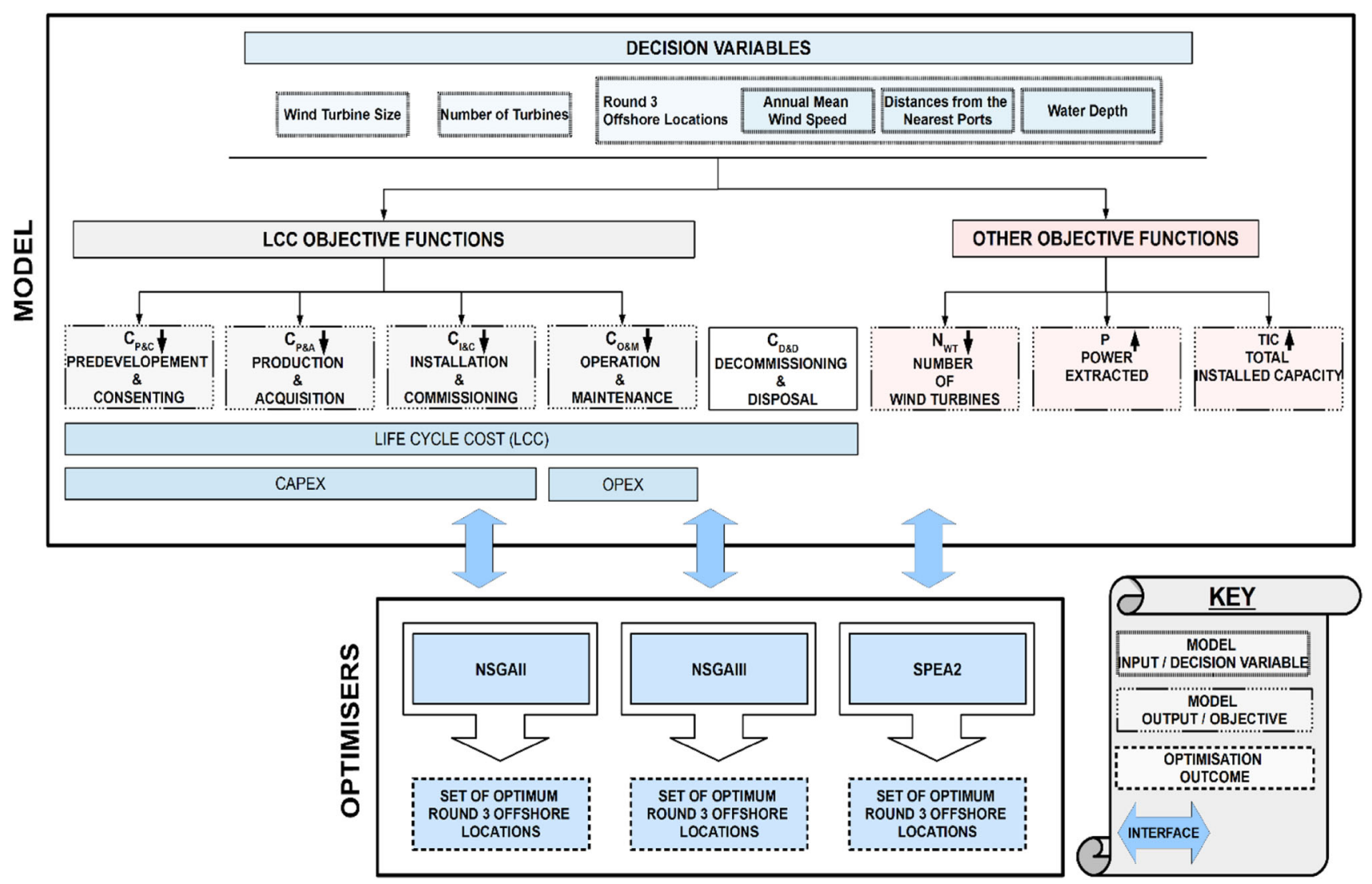

Fig. 1 Methodology layout

tin et al. 2013). One of the most important decisions arising when starting a new investment is the selection of a suitable offshore location and always requires extended effort. A methodology is proposed to help the decision-making process at these first stages of a wind farm investment considering the Round 3 zoned in the UK. Through this methodology, the location based on different physical aspects is selected.

The aim of this paper is to discover the optimum offshore Round 3 location based on financial costs and demonstrate the effectiveness of the underlying methods. The wind energy project costs associated with the design specifications of the site in conjunction with the turbine type and number of turbines should be numerically captured. This considers physical aspects unique to each offshore location, such as wind speed, water depth, and distance from appropriate construction ports, and will be modelled using life cycle cost (LCC) analysis. The best location should be discovered by considering the conflicting nature of the cost elements, so as to reduce overall cost at the early stages of a wind energy investment. Multi-objective optimisation algorithms will be coupled to the aforementioned model and used to reveal the interplay among the cost elements. To increase the effectiveness of the optimisation process and the diversity of the results, three different algorithms will be employed.

The contribution to knowledge is as follows. First, the combination of a newly developed prototype framework that includes economic modelling and optimisation process is assessed, so as to select the optimum offshore Round 3 location of a wind farm in the UK. Second, a set of non-dominated optimal solutions is suggested using the prototype framework. Both are expected to assist project developers and researchers at the first stages of the design of a wind farm.

The suggested methodology is depicted in Fig. 1. It comprises of individual modules, coupled with generic interfaces, so as to enable incremental development. Here, the physical aspects of each wind farm location (i.e., the wind speed, distance from the ports and water depth), the wind turbine size, and the number of turbines are considered, to manually select the optimum, economically efficient, and viable option (Shafiee et al. 2015).

The structure of this paper is as follows. A literature review in LCC analysis and the main phases will be explained. A description of the optimisation process and categories, and their benefits along with the most commonly used optimisation algorithms will be presented. Next, the methodology will follow. Finally, the results will be analysed and followed 
by a discussion. Future avenues will be drawn in the conclusions.

\section{Literature review}

\subsection{Multi-objective optimisation}

In real-world cases, multiple and conflicting objectives have to be improved simultaneously and multi-objective optimisation techniques have to be used, for example, minimising time versus energy efficiency (Branke et al. 2008).

During MOO, the decision space, the hyperplane that combines all the decision variables, is searched by evaluating the constraints and objectives. At the end of the process, a set of solutions is obtained and they are at least as many as the considered objectives. This is frequently called the Pareto Optimal Set or Pareto Front, where it is not possible to improve any objective without compromising in any of the others (Adinolfi et al. 2015).

MOO assists decision makers in appreciating the trade-off among conflicting objectives, before selecting the optimum solution for implementation, while understanding the interplay among the considered objectives. Some MOO studies can be found in Table 1 .

\subsubsection{SPEA}

Strength Pareto Evolutionary Algorithm (SPEA) is an evolutionary based algorithm and it is also an MOO algorithm. In other words, SPEA is an Evolutionary Multiple Objective algorithm or EMO. SPEA is closely related to other evolutionary algorithms such as the NSGA, Vector-Evaluated Genetic Algorithm (VEGA), and Pareto Archived Evolution Strategy (PAES). SPEA has two versions, i.e., SPEA and SPEA 2, an extension of the former. More extensions can be found under the name SPEA+ and iSPEA. The aim of this algorithm is to locate and maintain a collection of non-dominated solutions (Pareto front) by examining thoroughly the search area by following an evolutionary procedure.

SPEA discovers and maintains a set of Pareto optimal solutions. An evolutionary process is used to investigate through the search space. During the selection process, a utility function is used, where an assessment method for dominance is combined with a density estimator. An archive of the Pareto Front is kept separately from the population of potential solutions used in the evolutionary process, thus demonstrating a form of elitism (Brownlee 2011).

SPEA 2 was selected for this work due to its suitability for MOO problems (Brownlee 2011; Nalianda 2012). SPEA is appropriate for combinatorial and continuous function $\mathrm{MOO}$ problems. A binary representation can be used for continuous function optimisation problems along with classical genetic operators such as one-point crossover and point mutation. In SPEA 2, the size of the archive is commonly smaller than the size of the population. It is possible to implement optimisation in calculations of density (of the revealed solutions) and Pareto dominance. More can be found in Zitzler et al. (2001).

\subsubsection{NSGA}

NSGA stands for non-dominated sorting genetic algorithm and it is also an MOO algorithm and an EMO. Currently, there are three versions of the code: NSGA, NSGAII, and NSGAIII, among which the last two will be considered in this study. NSGAII has been employed on a number of optimisation problems, mostly with two objectives, whereas NSGAIII is expected to be more appropriate when the number of objectives increases (Yuan et al. 2014), as in this research.

For comparison purposes, the performance of all three selected optimisers is depicted in Fig. 2, where they were applied to a benchmark test function with three objectives. Ideally, the trade-off should be as much dense and wide as possible, so as to uniformly cover the performance of the objective space. In Fig. 2, the shape of a reference problem (which was not as complex as the developed LCC) is illustrated. The application of these algorithms in the optimum selection of the wind farm location, as a class of problems, has never been attempted before. As part of the contribution to knowledge and to demonstrate by evidence the effectiveness of the optimisers to deliver non-dominated solutions in real-world modelling, all three optimisers were trialled. The optimisers were considered to compare the quality of the solutions, irrespectively of their internal functions. All algorithms can yield satisfactory results and are tested in different sectors according to the literature. Frequently, using one of them is acceptable and has delivered satisfactory results. As expected, there are advantages and disadvantages for each method, which will be investigated further below. Hence, employing all three methods will highlight the differences among them, as certain algorithms behave better in certain problems (Wolpert and Macready 1997).

The class of NSGA algorithms was selected in this study, because it is suitable for MOO problems. NSGA is appropriate for continuous function MOO problems. A binary representation of a decision variable can be used along with classical genetic operators such as one-point crossover and point mutation. A real-valued representation is recommended for continuous function optimisation problems, which consequently requires specific genetic operators such as Simulated Binary Crossover (SBX) and polynomial mutation (Deb and Agrawal 1994; Jain and Deb 2014; Nalianda 2012). The number of divisions needs to be set in the NSGAIII algorithm. The divisions are a mechanism NSGAIII uses to control the spacing of a reference point as it progresses through the loops. 
Table 1 Multi-objective optimisation in RE systems

\begin{tabular}{|c|c|c|c|c|}
\hline Description & Refs. & Economic modelling & $\begin{array}{l}\text { Optimisation } \\
\text { algorithms }\end{array}$ & Renewable energy \\
\hline $\begin{array}{l}\text { An optimisation study is conducted } \\
\text { to find the optimum design of } \\
\text { switching converters so as to be } \\
\text { integrated with related renewable } \\
\text { technologies. Multi-objective } \\
\text { optimisation is performed with } \\
\text { associated conflicting objectives } \\
\text { for instance efficiency and } \\
\text { reliability, and finally, the } \\
\text { optimum solution is obtained } \\
\text { among ideal options from the } \\
\text { Pareto optimal ones }\end{array}$ & Adinolfi et al. (2015) & $\begin{array}{l}\text { Includes economic aspects } \\
\text { such as price minimisation } \\
\text { and cost saving }\end{array}$ & $\begin{array}{l}\text { Genetic } \\
\text { algorithm } \\
\text { NSGA II }\end{array}$ & Photovoltaic systems \\
\hline $\begin{array}{l}\text { A study on photovoltaic systems } \\
\text { and electro-thermal methods was } \\
\text { conducted. In the study, a } \\
\text { multi-objective optimisation was } \\
\text { suggested and applied to two } \\
\text { conflicting objectives; the } \\
\text { maximisation of the efficiency of } \\
\text { the solutions from Europe and } \\
\text { their cost minimisation }\end{array}$ & Graditi et al. (2014) & $\begin{array}{l}\text { Includes cost and reliability } \\
\text { performances }\end{array}$ & $\begin{array}{l}\text { Commercial } \\
\text { Power } \\
\text { optimiser }\end{array}$ & Photovoltaic systems \\
\hline $\begin{array}{l}\text { In this study, a number of scenarios } \\
\text { are investigated using } \\
\text { multi-objective optimisation } \\
\text { techniques that are applied to an } \\
\text { electrical energy storage system } \\
\text { investigating the connection with } \\
\text { renewable sources }\end{array}$ & Ippolito et al. (2014) & $\begin{array}{l}\text { Includes the minimization } \\
\text { of the total electricity } \\
\text { generation cost }\end{array}$ & $\begin{array}{l}\text { Genetic } \\
\text { algorithm } \\
\text { NSGA II }\end{array}$ & $\begin{array}{l}\text { Electrical Energy Storage } \\
\text { system for RE systems }\end{array}$ \\
\hline $\begin{array}{l}\text { Yeh and Chuang are using multiple } \\
\text { and conflicting objectives and } \\
\text { combine them with genetic } \\
\text { algorithms so as to find the } \\
\text { Pareto optimal solution in a } \\
\text { green supply chain case. In the } \\
\text { study, four conflicting objectives } \\
\text { and related green criteria were } \\
\text { carefully selected such as the } \\
\text { total cost, time etc. }\end{array}$ & Yeh and Chuang (2011) & $\begin{array}{l}\text { Includes the minimization } \\
\text { of the total cost and it } \\
\text { consists of the product } \\
\text { cost and transportation } \\
\text { cost }\end{array}$ & $\begin{array}{l}\text { Hybrid } \\
\text { combination of } \\
\text { two genetic } \\
\text { algorithms }\end{array}$ & $\begin{array}{l}\text { Green supply chain } \\
\text { problem that also } \\
\text { considers renewables }\end{array}$ \\
\hline $\begin{array}{l}\text { A methodology was created using } \\
\text { multi-objective optimisation to } \\
\text { maximise the energy harvested } \\
\text { from a photovoltaic module and } \\
\text { at the same time minimise the } \\
\text { mass of the module-integrated } \\
\text { converter }\end{array}$ & Mirjafari and Balog (2012) & $\begin{array}{l}\text { Includes cost and efficiency } \\
\text { objective functions }\end{array}$ & $\begin{array}{l}\text { Particle Swarm } \\
\text { Optimization } \\
\text { (PSO) }\end{array}$ & Photovoltaic systems \\
\hline $\begin{array}{l}\text { The total system cost and the } \\
\text { probability of deficiency of } \\
\text { power supply of Hybrid Electric } \\
\text { Systems (HRESs) are optimised } \\
\text { using NSGA II. The HRES } \\
\text { includes a wind turbine, a } \\
\text { photovoltaic panel and a battery. } \\
\text { NSGA II drives the optimisation } \\
\text { search, but it is led by a Chance- } \\
\text { Constrained-Programming-based } \\
\text { method to consider RE sources } \\
\text { uncertainty }\end{array}$ & Kamjoo et al. (2016) & $\begin{array}{l}\text { Includes the total cost of the } \\
\text { system }\end{array}$ & $\begin{array}{l}\text { Genetic } \\
\text { algorithm } \\
\text { NSGA II }\end{array}$ & $\begin{array}{l}\text { Hybrid Renewable Energy } \\
\text { System } \\
\text { (HRES)—includes wind } \\
\text { turbine and photovoltaic } \\
\text { panels }\end{array}$ \\
\hline
\end{tabular}


Table 1 continued

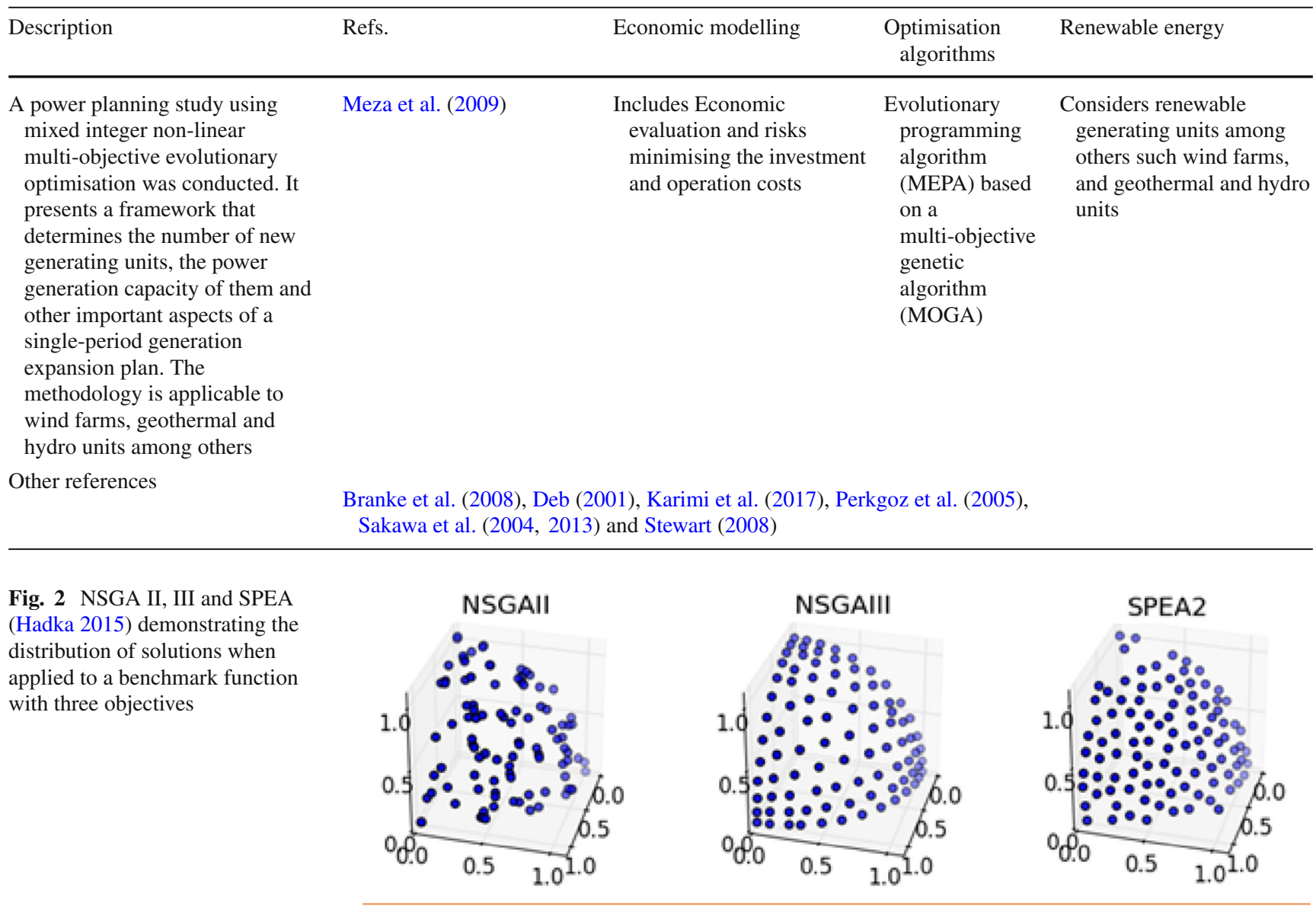

It is suggested by Chiang (2014), Deb and Jain (2014) and Jain and Deb (2014) to use 12 divisions, where the domain of each of the many objectives is separated into regions using reference points to define normalised hyperplanes, for greater effectiveness in the discovery process.

Both optimisers are considered as the state-of-the-art multi-objective algorithms, and they are selected for this study. In general, the optimisation problem can be solved through genetic algorithms, Tabu Search, Simulated Annealing, and other Heuristic methods (Momoh and Reddy 2014). A few methods that can also be applied to this study are the following: multi-objective evolutionary algorithm based on decomposition (MOEA/D), covariance matrix adaptation evolution strategy (CMAES), the third evolution step of generalized differential evolution (GDE3), indicator-based evolutionary algorithm (IBEA), optimized multi-objective particle swarm optimiser (OMOPSO), speed-constrained multi-objective PSO (SMPSO), etc. (Hadka 2015). However, the SPEA2 algorithm has not been considered yet for that type of applications.

Evolution and genetic algorithms are used throughout the literature in many energy-related sectors. Karimi presented an approach that links a multi-objective genetic algorithm to the design of a floating wind turbine. By varying nine design variables related to the structural characteristics of the support structure, multiple concepts of support structures were modelled and linked to the optimiser. The aim is to minimise the economic costs (as a combination of the mooring system, the anchor, and the offshore floating platform) and maximise the turbine performance (standard deviation of nacelle acceleration. The Pareto Front contained a wide number of results that reflect solutions of either the single-body platforms or tension-leg platforms or multi-body platforms. In the future steps, it was suggested to optimise the levelised cost of energy and to consider a different parameterisation scheme both of which could extend to the present research (Karimi et al. 2017).

Yan suggests a methodology that includes genetic algorithms and the analytical hierarchy process decision-making method in a study related to green suppliers (Yan 2009). The design of a new optimisation algorithm is proposed in Saavedra-Moreno et al. (2011), to optimise the layout of turbines in a wind farm. New aspects were considered for the objectives, such as the shape of the wind farm, a range of costs 
(expressed in a benefit for investment), and orography. The optimisation algorithm is based on evolutionary algorithms and is seeded by a greedy approach, where experimental comparisons have been demonstrated.

Five different types of optimisation algorithms were used in Elkinton et al. (2008) to optimise the layout of a wind farm. As it was also mentioned in Cagan et al. (2002), solutions of higher quality can be discovered using algorithms with stochastic elements. However, these operate at a much slower speed, than the deterministic counterparts. In fact, in Elkinton et al. (2008), combining genetic algorithms with heuristics was more effective and faster than using only one of them. In this particular instance, it was suggested to use layout optimisation in small areas, or, at least, focus in good areas before launching a bigger optimisation case.

Another approach, presented in Wan et al. (2012), was used to optimise the layout of a wind farm (micro-siting optimisation: choosing the type and location of wind turbines) by considering continuous space and using particle swarm optimisation techniques. A special local search scheme was also introduced in the optimisation algorithm, to successfully speed up the process, where realistic solutions were discovered that delivered more electricity. In Papatheou et al. (2015), an evolutionary optimisation algorithm is used in the area of supervisory control and data acquisition or SCADA in a Swedish offshore wind location called Lillgrund for monitoring purposes to optimise and predict the energy production from every wind turbine in a wind farm considering related data from other wind turbines. Finally, in González et al. (2010), evolutionary algorithms are applied in a wind farm-related optimisation problem. The configuration of the layout of the turbines is optimised based on a cost model. The problem is very complex, since the optimum layout has been troubling many specialists for years. The suitability of the suggested evolutionary techniques is proven in the study.

\subsection{Life cycle cost modelling}

Life cycle cost was established by the Federal Energy Management Program to evaluate economically energy, water conservation, and RE projects for federal facilities. A guide was created in a handbook in Fuller and Petersen (1996), where the methodology and criteria were evaluated and presented. LCC analysis can evaluate and suggest cost reductions throughout a project's life. The outcome of the analysis can provide useful information in an investment and can direct decision making from the initial stages of a new project.

Calculating the LCC of an offshore wind project involves five stages from the predevelopment to the decommissioning phase, and there is not a common universal reference point for wind projects. In Shafiee et al. (2015), a parametric whole life cost framework for an offshore wind farm and a cost breakdown structure is presented and analysed. LCC analysis is essential for the insurers, wind farm operators, and investors to ensure a cost-efficient long and profitable investment plan to produce power.

LCC analysis gains more ground over the years because of the larger scale in wind projects. For example, Nordahl (2011) studied the advantages and disadvantages of the transition to offshore wind and proposed an LCC model of an offshore wind development. However, the study mainly centres in a simplified model and especially the operation and maintenance stage of the LCC analysis and it is suggested that there can be a further full-scale LCC framework in the future.

A study that states legal, financial, etc. related problems of wind turbines that are positioned both onshore and offshore is described in Angelakoglou et al. (2014) and involves an assessment using the LCC analysis methodology to select the best option, environmentally, energywise, and economically. Martínez et al. (2009) offer further insight in LCC analysis for a wind turbine throughout its whole life beginning from the manufacturing and installation to the decommissioning. This aims to quantify the impact of each stage along with important aspects such as manufacturing, transportation to site, and material waste.

The importance of the LCC analysis and an economic life cost-related model in three different offshore floating wind devices was presented in Laura and Vicente (2014). This study aims to develop a framework and minimise some of the most important costs in a floating type of turbine making the floating devices a more attractive investment. In the same direction, Myhr et al. (2014) also studies five different types of floating wind turbine concepts in one offshore location and compares them using LCC-related features. The water depth was found to have the most significant impact on the total cost.

According to Shafiee et al. (2015), LCC analysis includes costs calculated from several stages of the wind project such as the predevelopment and consenting $\left(C_{\mathrm{P} \& \mathrm{C}}\right)$, production and acquisition $\left(C_{\mathrm{P} \& \mathrm{~A}}\right)$, installation and commissioning $\left(C_{\mathrm{I} \& \mathrm{C}}\right)$, operation and maintenance $\left(C_{\mathrm{O} \& \mathrm{M}}\right)$, and decommissioning and disposal $\left(C_{\mathrm{D} \& \mathrm{D}}\right)$ stage. Since foundations and support structures moved further towards deeper waters, Round 3 locations moved further away from the shore, and larger scale wind turbines are now becoming more common along with transportation and delays especially through vessels, the cost has been increased considerably. This study follows the LCC framework that was developed in Shafiee et al. (2015) and investigates different Round 3 offshore locations using it as common ground to select the most costefficient one. Through the study, the main aspects that impact the final costs are discussed. 


\subsection{Selecting an offshore location}

To the author's knowledge, there are no studies that combine the concept of LCC with optimisation techniques with a focus on the individual LCC costs, to find the optimum offshore location for wind farm projects. Moreover, there are no studies that consider objectives based on economic figures and select the optimum Round 3 offshore location in the UK. In fact, for the selection of the location, there is very limited work accessible and with a small amount of focused and related criteria on this topic.

In the literature, many RE and location selection studies can be found, but the findings and the formulation of the problems provided follow a different direction. For example, using goal programming, the offshore location for a wind farm installation was selected in Jones and Wall (2015). The study involves Round 3 locations in the UK, while shows its flexibility to combine decision-making methods. This work shows the energy production, costs, and multi-criteria nature of the problem also considering some important factors related to environmental, social, technical, and economic aspects. The LCC analysis and their formulation into an MOO problem were not employed in the application. According to Jones and Wall (2015), multi-objective modelling techniques for both onshore and offshore wind farm are quite underdeveloped. The present study focuses on a methodology to fill this gap by linking MOO with LCC as objective functions and compares optimisation algorithms to select the optimum solution.

Another study on offshore locations is provided in Cradden et al. (2016) for an RE platform using multiple criteria and geographical information systems (GIS). A range of problems that exist around offshore RE platforms have been reviewed and a combination of criteria has been selected for the Atlantic facing shores in Europe. The potential risks were studied and it was found that the extreme weather conditions show the necessity of a compromise between the designing costs and the extra energy production. Very important factors were also the lack of ports with suitable available construction infrastructure that results in under-exploited sites, access problems, and weather window conditions, even during the summer months (Cradden et al. 2016). Although the study is very thorough, it is mostly focused on environmental, geographical, and weather issues that are out of scope because of the economic nature of the objectives and related criteria.

\section{A framework for the optimisation of deployment sites for Round 3 wind farms in the UK}

In Espinosa (2014) and Shafiee et al. (2015), a whole LCC formulation is provided and this study follows the steps and phases of the analysis for the optimisation problem. Assump- tions and useful data in the modelling of the problem can be found in references 4COffshore (2017c), Dicorato et al. (2011), Espinosa (2014), Laura and Vicente (2014), Shafiee et al. (2015), The Crown Estate (2017) and Wind Energy The Facts (2017). Based on the previous work, a new model was developed so as to be coupled with the optimisation algorithms and drive the optimisation search.

The framework described in this section assesses the effectiveness of a suggested methodology to discover the optimum Round 3 offshore locations in the UK and improve the decision-making processes. Conceptually, the framework comprises of a model and an optimisation algorithm. The flow chart in Fig. 1 shows the optimisation model that includes seven objectives, four LCC-related objectives, described in Shafiee et al. (2015), and three additional objectives. Optimising seven objective functions at the same time, which are conflicting (from the mathematical formulation below), classifies the problem as multi-objective and it is considered rather complicated because of the interplay of the objectives and the nature of the variables.

The LCC model described in Shafiee et al. (2015) is used in this study and provided below in detail.

The LCC is calculated as follows:

$\mathrm{LCC}=C_{\mathrm{P} \& \mathrm{C}}+C_{\mathrm{P} \& \mathrm{~A}}+C_{\mathrm{I} \& \mathrm{C}}+C_{\mathrm{O} \& \mathrm{M}}+C_{\mathrm{D} \& \mathrm{D}}$

LCC: Life cycle cost

$C_{\mathrm{P} \& \mathrm{C}}$ : Predevelopment and consenting cost

$C_{\mathrm{P} \& \mathrm{~A}}$ : Production and acquisition cost

$C_{\mathrm{I \& C}}$ : Installation and commissioning

$C_{\mathrm{O} \& \mathrm{M}}$ : Operation and maintenance cost

$C_{\mathrm{D \& D}}$ : Decommissioning and disposal

$C_{\mathrm{P \& C}}=C_{\text {projM }}+C_{\text {legal }}+C_{\text {surveys }}+C_{\text {eng }}+C_{\text {contingency }}$

$C_{\text {projM }}$ : Project management cost

$C_{\text {legal }}:$ Legal cost

$C_{\text {surveys: }}$ : Survey cost

$C_{\text {eng: }}$ : Engineering activities cost

$C_{\text {contingency: }}$ Contingency cost

$C_{\mathrm{P \& A}}=C_{\mathrm{WT}}+C_{\mathrm{SS}}+C_{\mathrm{PTS}}+C_{\text {monitoring }}$

$C_{\mathrm{WT}}$ : Wind turbine procurement cost

$C_{\mathrm{SS}}$ : Support structure/foundation cost

$C_{\text {PTS }}$ : Electricity transmission cost

$C_{\text {monitoring: }}$ :Monitoring cost

$C_{\mathrm{I} \& \mathrm{C}}=C_{\mathrm{I} \& \mathrm{C}-\text { port }}+C_{\mathrm{I} \& \mathrm{C}-\text { comp }}+C_{\text {comm }}+C_{\mathrm{I} \& \mathrm{C} \text {-ins }}$

$C_{\text {I\&C-port }}:$ Port-related cost 


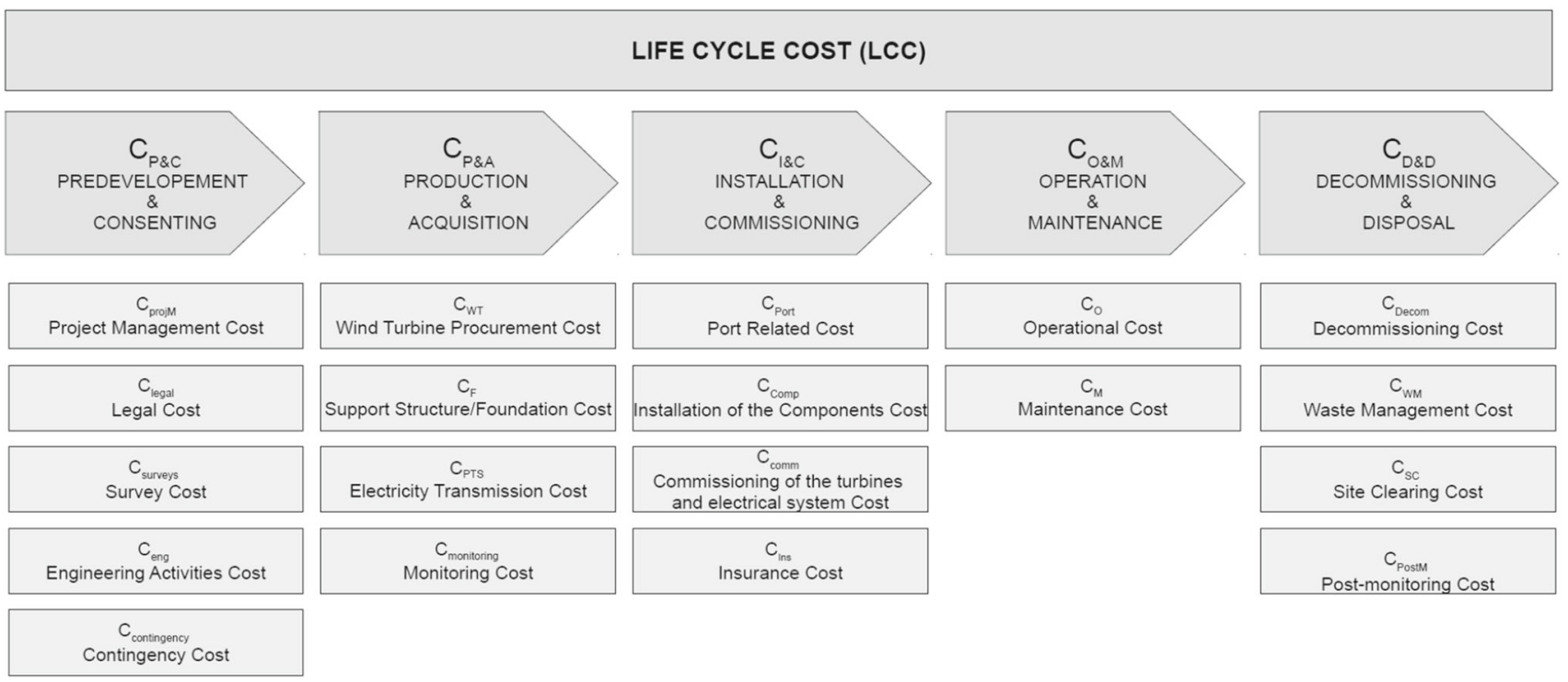

Fig. 3 Life cycle cost (LCC) break down (Shafiee et al. 2015)

$C_{\text {I\&C-comp }}$ : Installation of the components cost

$C_{\text {comm: }}$ : Commissioning of the wind turbines and electrical system cost

$C_{\text {I\&C-ins }}:$ Construction insurance cost

$C_{\mathrm{O} \& \mathrm{M}}=C_{\mathrm{O}}+C_{\mathrm{M}}$

$C_{\mathrm{O}}$ : Operational cost

$C_{\mathrm{M}}$ : Maintenance cost

$C_{\mathrm{D} \& \mathrm{D}}=C_{\mathrm{decom}}+C_{\mathrm{WM}}+C_{\mathrm{SC}}+C_{\mathrm{postM}}$

$C_{\text {decom: }}$ : Decommissioning cost

$C_{\text {WM: }}$ : Waste management cost

$C_{\text {SC }}$ : Site clearing cost

$C_{\text {postM: }}$ : Post-monitoring cost

$$
\begin{aligned}
\mathrm{CAPEX} & =C_{\mathrm{P} \& \mathrm{C}}+\mathrm{C}_{\mathrm{P} \& \mathrm{~A}}+C_{\mathrm{I} \& \mathrm{C}} \\
\mathrm{OPEX} & =C_{\mathrm{O} \& \mathrm{M}}
\end{aligned}
$$

\section{CAPEX: Capital expenditures \\ OPEX: Operating expenses}

More can be found in Shafiee et al. (2015).

The present study only considers the first four life cycle costs (depicted in Fig. 3) in the proposed methodology, because the aim is to understand the interplay between the CAPEX and OPEX costs to improve the decision-making process. Both these costs are considered to drive investment decisions, so as to prevent potential risks and issues when beginning a wind project by the developers.
As it is depicted in Fig. 1, the first four objectives are the costs from the LCC analysis. More specifically, the present model includes the predevelopment and consenting, production and acquisition, installation and commissioning, and finally operation and maintenance costs. The decommissioning and disposal cost is not considered at this stage. All of the cost-related objectives are minimised, as shown in Fig. 1. The mapping between the variables and the objectives that are estimated using the LCC analysis is depicted in Fig. 4. In this representation, the number of turbines, the distance from the ports, the water depth, and the power rate, which is determined by the wind turbine size shown in the specifications in Table 3, are the decision variables, as shown in Fig. 1.

The last three objectives are the number of turbines (NWT), the power that is extracted (P) from each offshore site and the total installed capacity (TIC), which are minimised, maximised, and maximised, respectively. The power extracted is calculated by the specific mean annual wind speed of each location along with the characteristics of each wind turbine both of which are considered inputs (listed in Table 2). The TIC is calculated by the number of turbines and the rated power of each of them.

The power extracted in this optimisation model is maximised and it is calculated for each site and each wind turbine, respectively, from

$P=\frac{1}{2} A C_{\mathrm{p}} \rho u^{3}$

A: Area of the wind turbine

$\rho$ : Air density

$C_{\mathrm{p}}$ : Power coefficient 


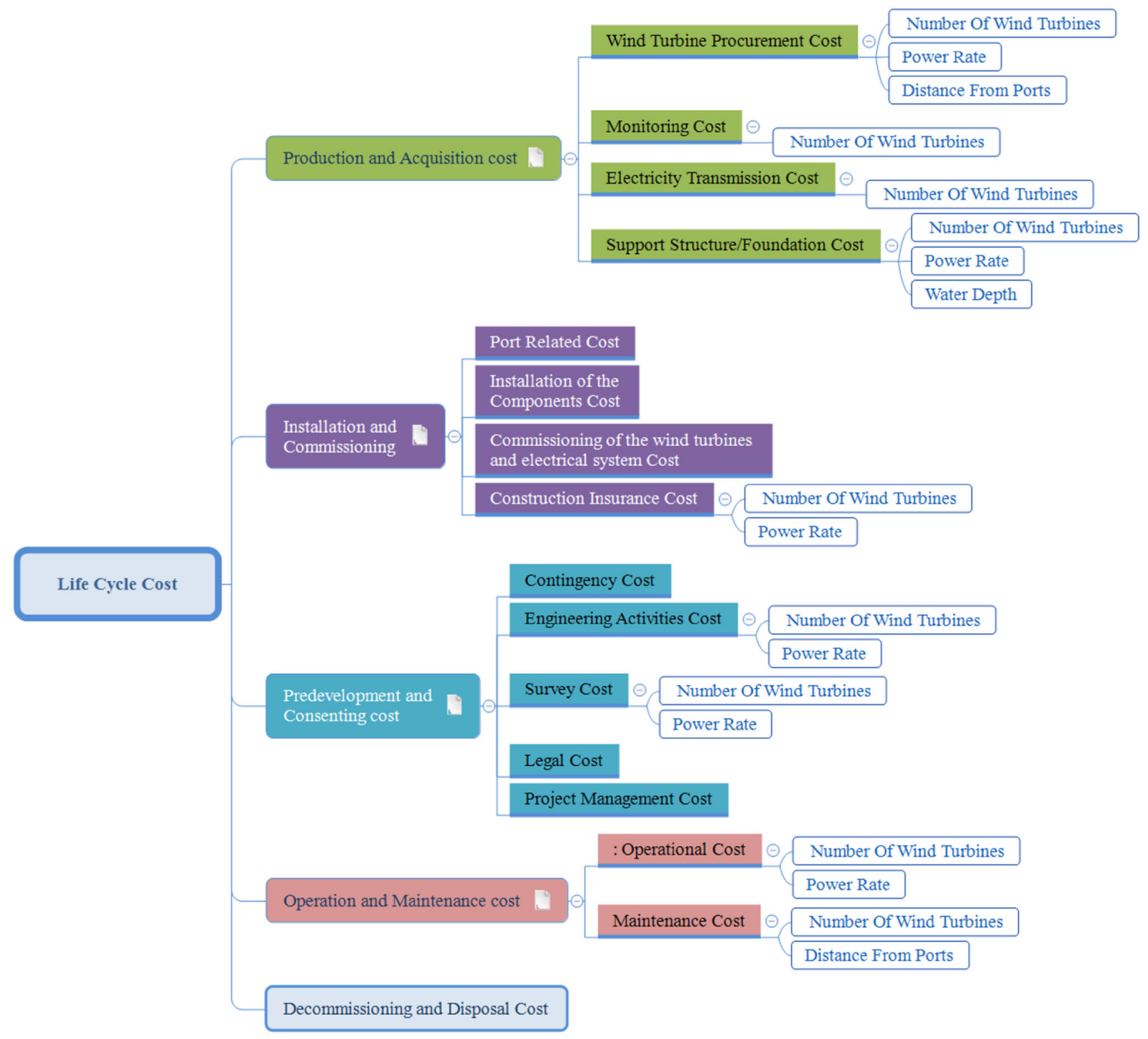

Fig. 4 Mapping the decision variables in LCC model

$u$ : Mean annual wind speed of each specific site

The last objective of the model is the total installed capacity (TIC) of the wind farm is calculated for every solution and it is maximised:

$\mathrm{TIC}=P_{\mathrm{R}} \times \mathrm{NWT}$

$P_{\mathrm{R}}:$ Rated power

NWT: Number of turbines

For the selection of the optimum offshore wind farm location, physical aspects of each location, i.e., wind speed, water depth, and distance from designated construction ports, are considered. A list of ports was acquired from Department of Energy and Climate Change (2009), Marine Traffic
Marine traffic (2017) and UK Ports Directory (2017). The list contains designated, appropriate, and sufficient construction ports that are suitable for the installation, manufacturing, and maintenance works for wind farms. New ports are agreed to be built for the conveniences of new wind farms. This study will consider only the parts and sites depicted in Fig. 5

For the distances from the ports calculation, QGIS was used. QGIS is an Open Source licensed Geographic Information System (GIS), which is a part of the Open Source Geospatial Foundation (OSGeo) (QGIS). The distances were calculated by the assumption of the nearest port to the individual wind farm, in a straight line. The specifications in Table 2 were acquired from 4COffshore (2017c); for each offshore location, a special profile was created including the 


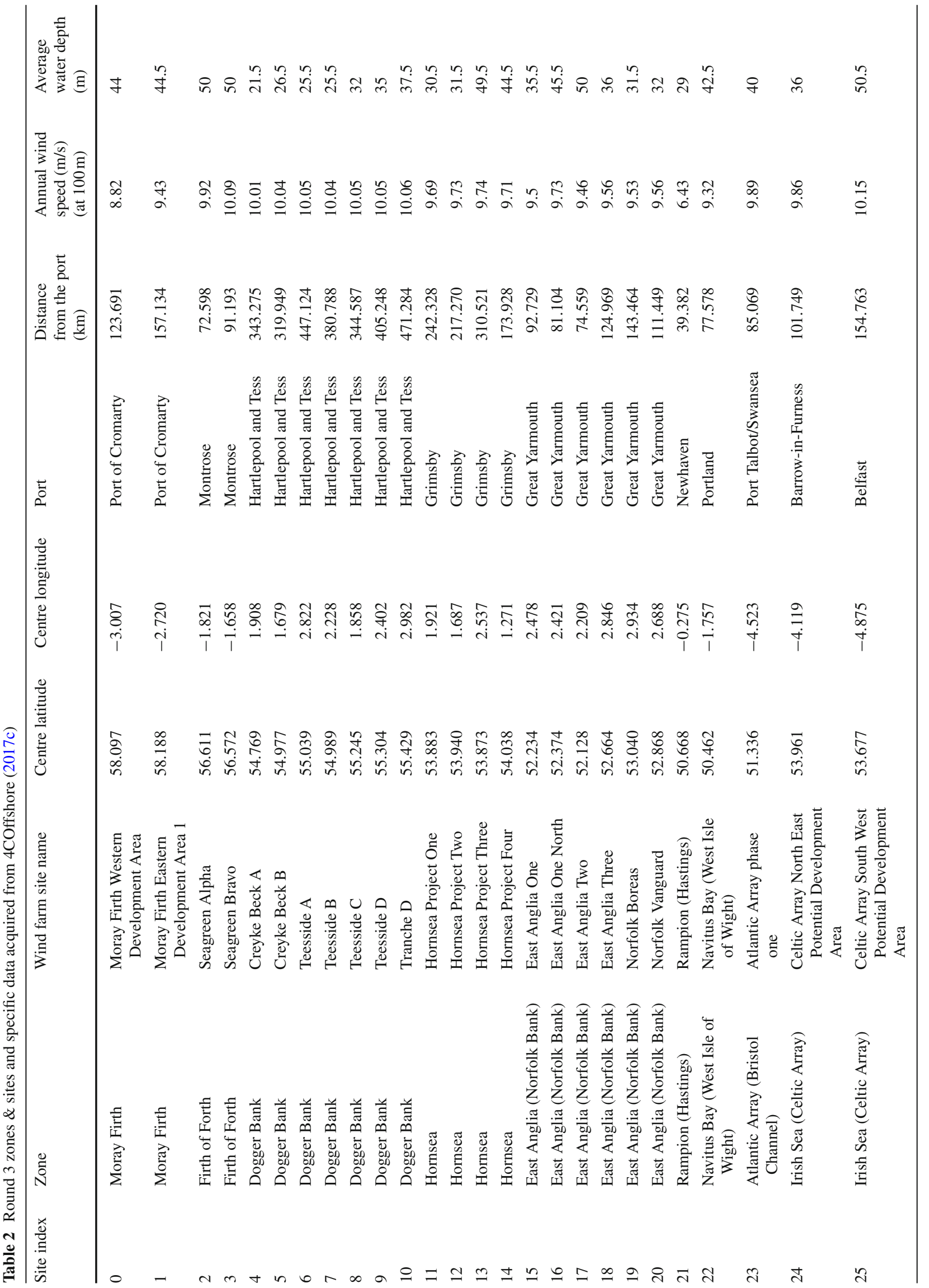




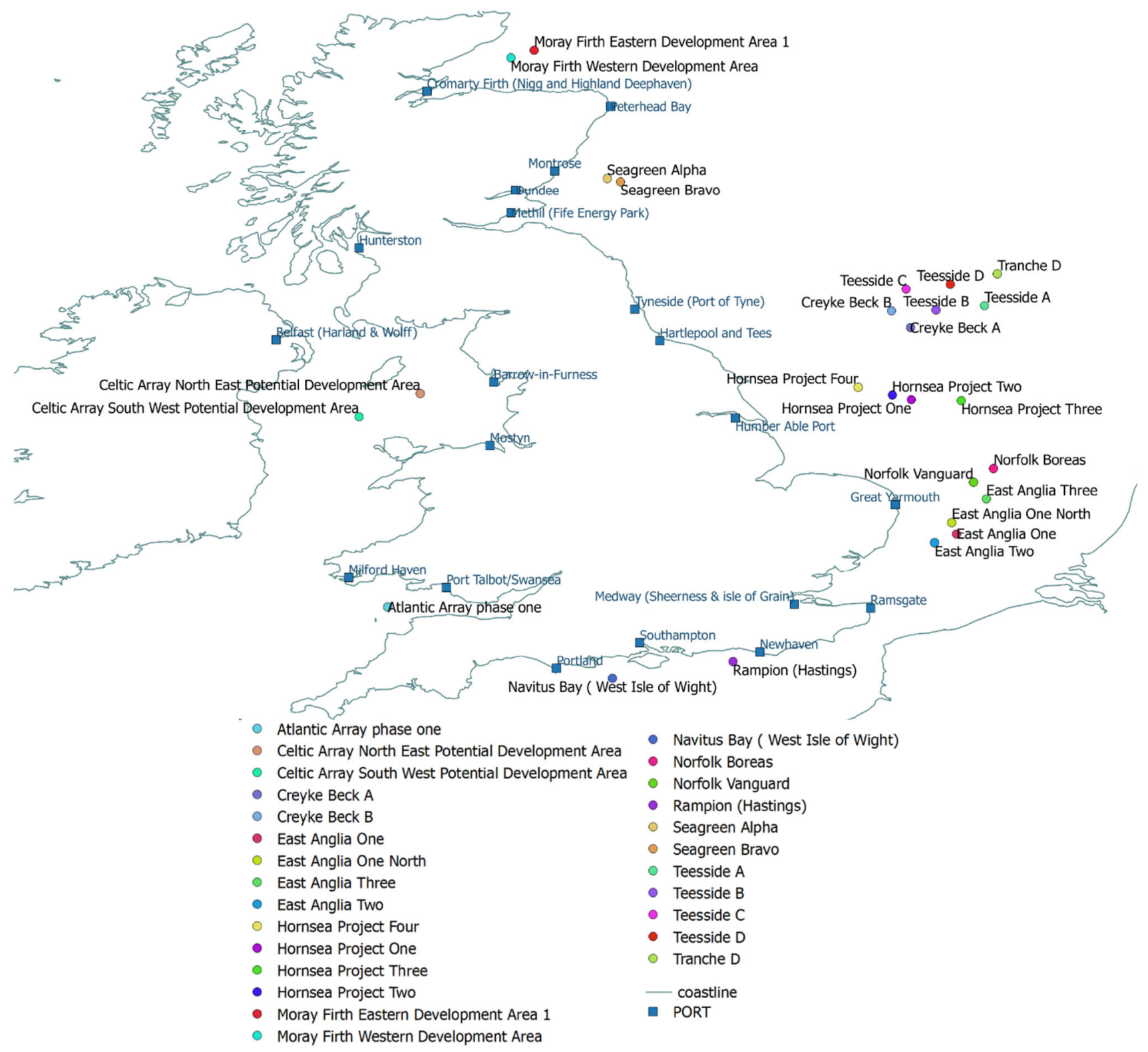

Fig. 5 Round 3 offshore location around the UK using QGIS

coordinated, the distances to the shore and port, annual wind speed, and average site water depth.

Table 2 shows among various data, the locations that each of these zones contains. Each location correlates with their specific data used in this problem.

Table 3 lists the specifications of the turbines that are considered in this study. These were extracted from reference turbines in 4COffshore (2017d).

The optimisation problem formulates as follows:

$$
\begin{array}{ll}
\text { Minimise } & C_{\mathrm{P} \& \mathrm{C}}, C_{\mathrm{P} \& \mathrm{~A}}, C_{\mathrm{I} \& \mathrm{C}}, C_{\mathrm{O} \& \mathrm{M}}, \mathrm{NWT},(-\mathrm{P}),(-\mathrm{TIC}) \\
\text { Subject to } & 0 \leq \text { site index } \leq 25, \\
& 0 \leq \text { turbine type index } \leq 6 \\
& 50 \leq \text { number of turbines } \leq 450,
\end{array}
$$

where the objectives are described above.

The site index and turbine-type index are specified in Tables 2 and 3, respectively. In the formulation, minimising the negative TIC and $\mathrm{P}$ is equivalent to their maximisation. The number of turbines was deliberately selected both as variable and as objective so as to minimise the CAPEX.

The optimisation modelling has been completed using the library platypus in python (Hadka 2015) and the selected optimisation algorithms are NSGA II, NSGA III with 12 divisions, and SPEA 2. For all the algorithms, the default implementations were employed and the stopping criteria were set to 10,000 iterations. 
Table 3 Turbine specifications

\begin{tabular}{lllll}
\hline Turbine type index & Rated power $(\mathrm{MW})$ & Rotor radius $(\mathrm{m})$ & Hub height $(\mathrm{m})$ & Total weight $(\mathrm{t})$ \\
\hline 0 & 10 & 95 & 125 & 1200.5 \\
1 & 8 & 82 & 123 & 965 \\
2 & 7 & 77 & 120 & 955 \\
3 & 6 & 70 & 100 & 656 \\
4 & 5 & 63 & 107 & 707.5 \\
5 & 3.6 & 53.5 & 83.5 & 476 \\
6 & 3 & 45 & 80 & 362.6 \\
\hline
\end{tabular}

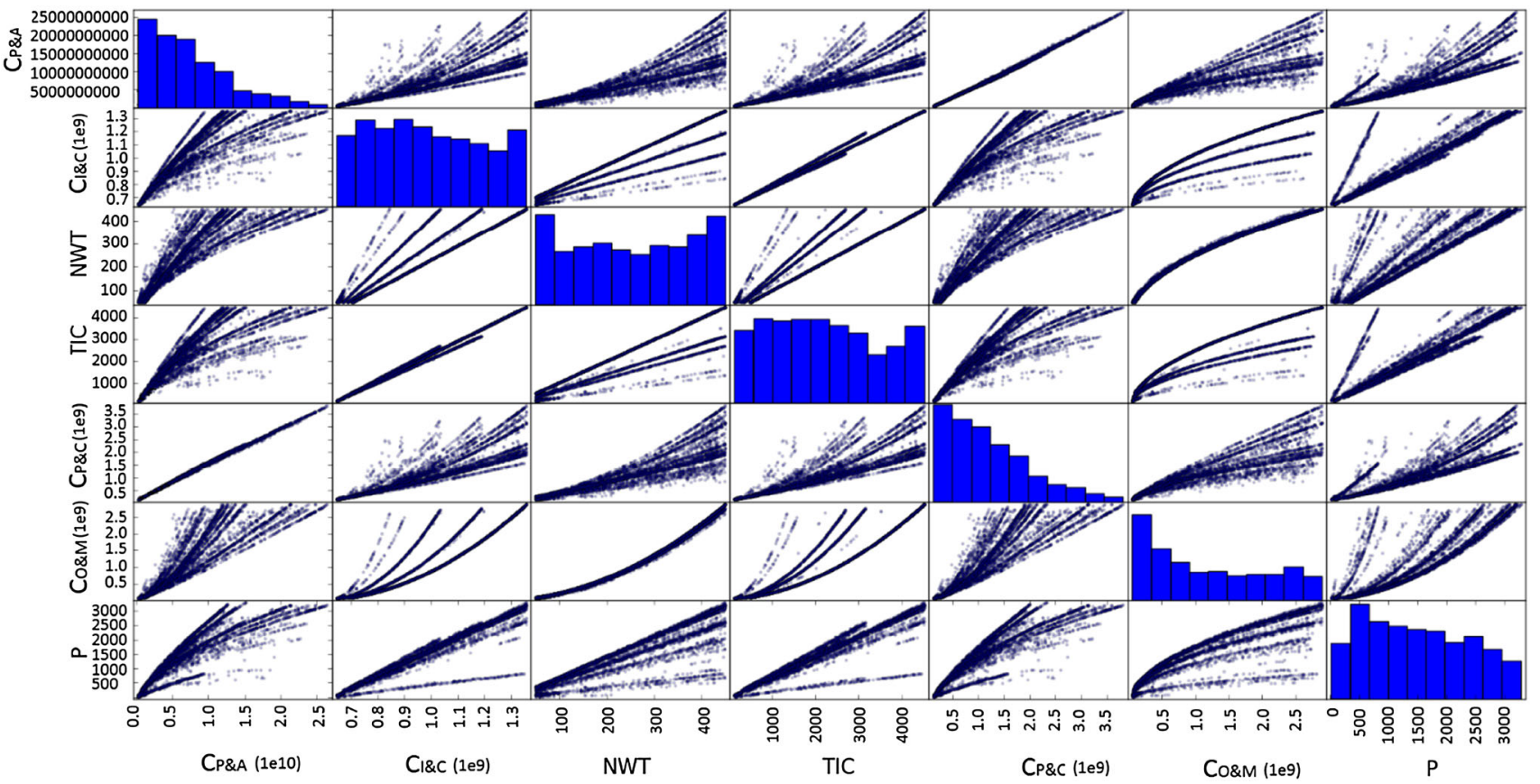

Fig. 6 Scatter plot matrix among the seven objectives, i.e., $C_{\mathrm{A} \& \mathrm{P}}, C_{\mathrm{P} \& \mathrm{C}}, C_{\mathrm{I} \& \mathrm{C}}, C_{\mathrm{O} \& \mathrm{M}}, \mathrm{NWT}, \mathrm{P}$, and TIC using NSGAII

In this study, a comparison among the pareto front solutions from each optimiser is conducted, where each optimiser delivered a non-dominated trade-off with the best possible solutions for offshore wind farm locations.

\section{Results}

The pareto front solutions from every algorithm and their trade-offs are presented. Although the variables are discrete in nature, the revealed trade-offs appear to be continuous. Each pareto front solution consists of the wind farm location, number of turbines (NWT), type of turbine, power extracted (P) for the specific site, total installed capacity (TIC) (i.e., the total capacity of the wind farm), and the life cycle costs (i.e., $C_{\mathrm{P} \& \mathrm{~A}}, C_{\mathrm{P} \& \mathrm{C}}, C_{\mathrm{I} \& \mathrm{C}}$, and $C_{\mathrm{O} \& \mathrm{M}}$ ).

A scatter plot matrix was considered as the best option to visualise a seven-dimensional problem and it is depicted from Figs. 6, 7, 8, 9, 10, and 11. In Figs. 6, 8, and 10, seven objectives, i.e., $C_{\mathrm{P} \& \mathrm{~A}}, C_{\mathrm{P} \& \mathrm{C}}, C_{\mathrm{I} \& \mathrm{C}}, C_{\mathrm{O} \& \mathrm{M}}, \mathrm{NWT}$, P, and TIC, are illustrated, and in Figs. 7, 9, and 11, the CAPEX, OPEX, NWT, P, and TIC are also provided. This is part of the Pareto Front, as it was discovered by the optimisers. In the main diagonal of the figure, the histograms represent the concentration of points in ten buckets of equal size. All the trade-offs are continuous, which means that there is not any (discontinuous) gap in performance.

\subsection{NSGA II}

In Figs. 6 and 7, the revealed trade-offs demonstrate that non-dominated solutions were discovered. However, certain areas were not explored thoroughly. For instance, the plot of ' $P$ versus NWT' illustrates that there is a strong upper limit, as expected from the nature of the model. In addition, in the same plot, it is obvious that the majority of solutions are 


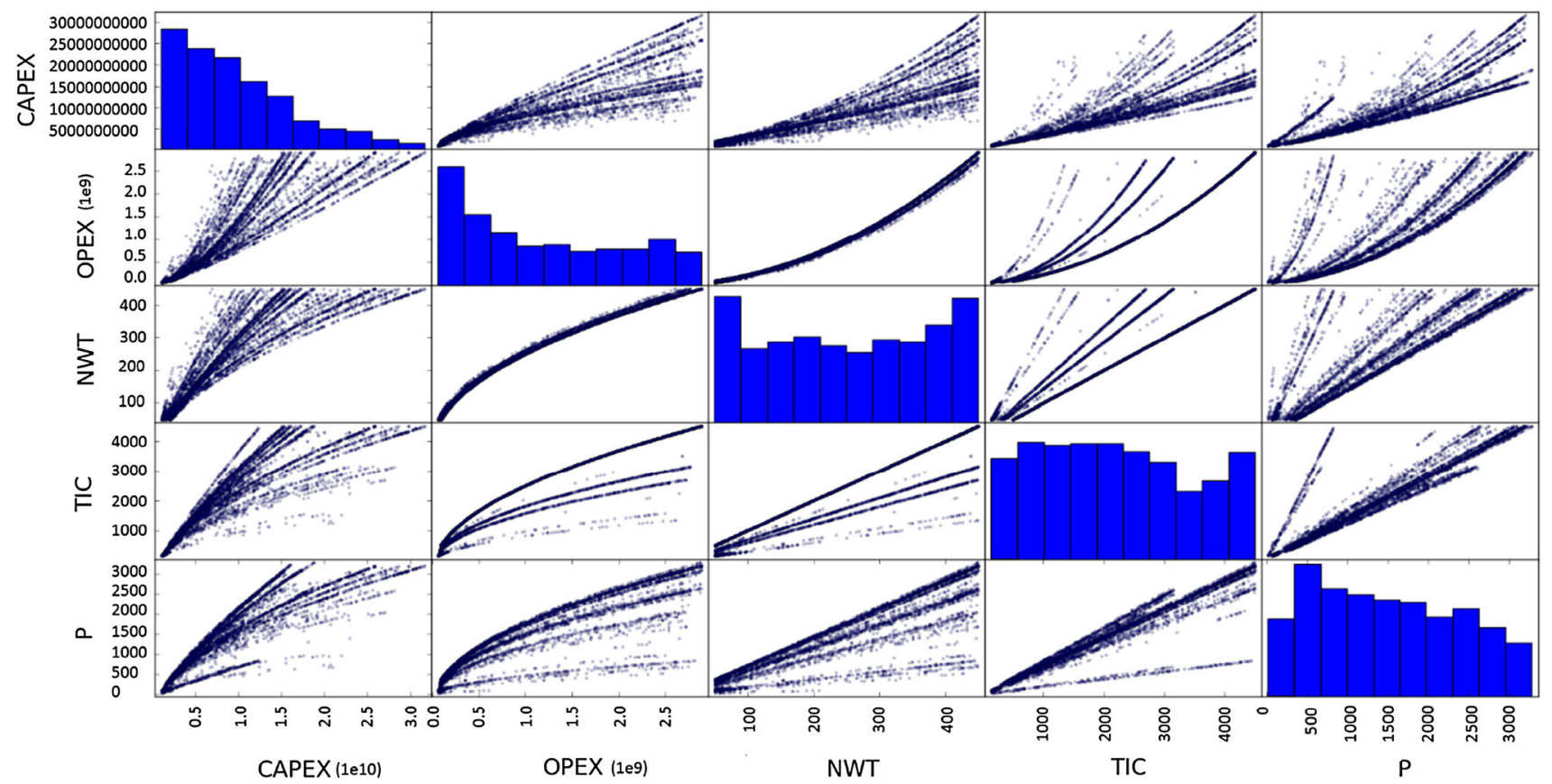

Fig. 7 Scatter plot matrix among CAPEX, OPEX, NWT, P, and TIC using NSGAII

focused on the upper bound, whereas below that, the number of points explored is scarce. This practically means that the optimiser quickly identified chromosomes with good performance and used the computational budget towards exploring along this direction. This pattern applies to most of the plots. Plots whose performance has a pattern similar to ' $C_{\mathrm{O} \& \mathrm{M}}$ versus $C_{\mathrm{I} \& \mathrm{C}}$ ' also demonstrate that certain performance routes were discovered and followed throughout the optimisation search. This explains the solid legs within the swarm of solutions. The bottom area of ' $P$ versus $C_{\mathrm{P} \& \mathrm{~A}}$ ' illustrates that a few areas of dominated performance (sporadic solutions) were discovered, but were not further investigated. Finally, ' $C_{\mathrm{P} \& \mathrm{C}}$ versus $C_{\mathrm{P} \& \mathrm{~A}}$ ', 'TIC versus $C_{\mathrm{I} \& \mathrm{C}}$ ', and ' $C_{\mathrm{O} \& \mathrm{M}}$ versus NWT' vary in harmony.

By interactively investigating the results, the following behaviour was identified. Each of the legs of the plot 'TIC versus $C_{\mathrm{O} \& \mathrm{M}}$ ' is linked to a particular wind turbine. Then, by varying the combination of the number of turbines and the site, a wide range of values of the cost element can be obtained. This is more obvious in the PFs discovered by NSGAIII because of the continuous points discovered for the same type of plot, whereas this would be very hard to spot in the results from NSGAII. This feature could be integrated into a process to detect any hidden performance relationships.

\subsection{NSGA III}

Compared to NSGAII, NSGAIII was also found to behave better when the number of objectives increases (relative to the other two optimisers), as expected by definition. Hence, the final results appear more uniform, as shown in Figs. 8 and 9. Consequently, the trade-offs for certain pairs of objectives are much more complete (in terms of the distance between any two points) and richer (in terms of a number of points within a relatively narrow area). It seems that the chromosomes covered a wider spectrum of solutions. In NSGA III, the 'NWT versus $C_{\mathrm{O} \& \mathrm{M}}$ ' present the most straightforward relationship as they are approaching an exponential trend. As before, the same three combinations clearly vary in harmony. In general, this demonstrates the suitability of NSGAIII in such problems (and will be considered as the main optimiser in the next stages of the research).

\subsection{SPEA2}

The performance of SPEA2 is depicted in Figs. 10 and 11. Fundamentally, the same characteristics can be observed. However, SPEA2 stands between NSGAII and NSGAIII, in terms of trade-off findings. It discovered more diverse solutions than NSGAII but less diverse than NSGAIII.

\section{Discussion}

Optimum locations for a wind farm have been discovered using three different MOO algorithms, NSGA II, NSGA III, and SPEA 2 and using the LCC analysis, to achieve costefficient solutions. The results follow a consistent trend and they seem to be in relative agreement. TIC, $C_{\mathrm{P} \& \mathrm{~A}}, C_{\mathrm{I} \& \mathrm{C}}$, and $C_{\mathrm{P} \& A}$ vary in harmony, as shown in Figs. 6,8 , and 10, which 


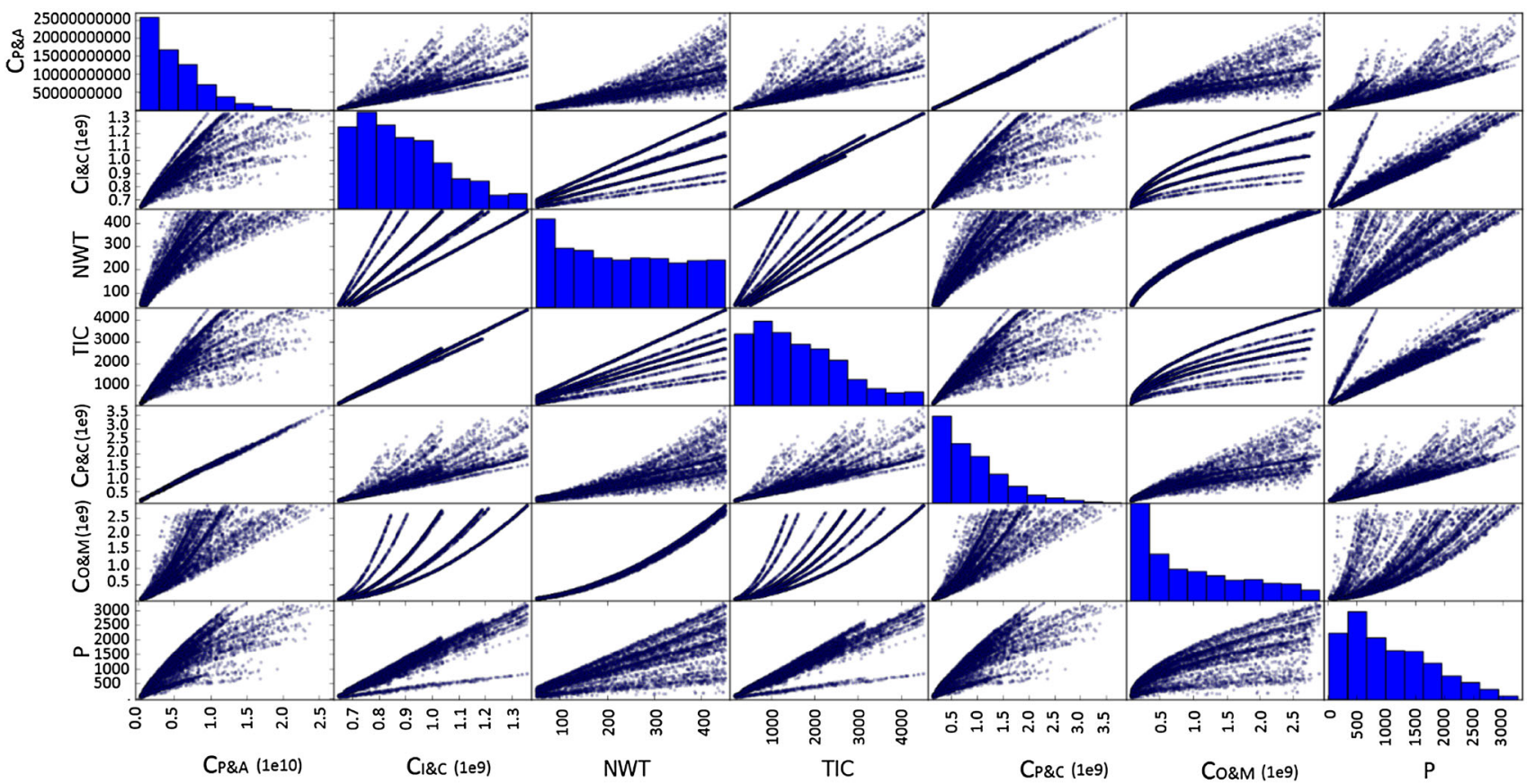

Fig. 8 Scatter plot matrix among the seven objectives, i.e., $C_{\mathrm{A} \& \mathrm{P}}, C_{\mathrm{P} \& \mathrm{C}}, C_{\mathrm{I} \& \mathrm{C}}, C_{\mathrm{O} \& \mathrm{M}}, \mathrm{NWT}, \mathrm{P}$, and TIC using NSGAIII

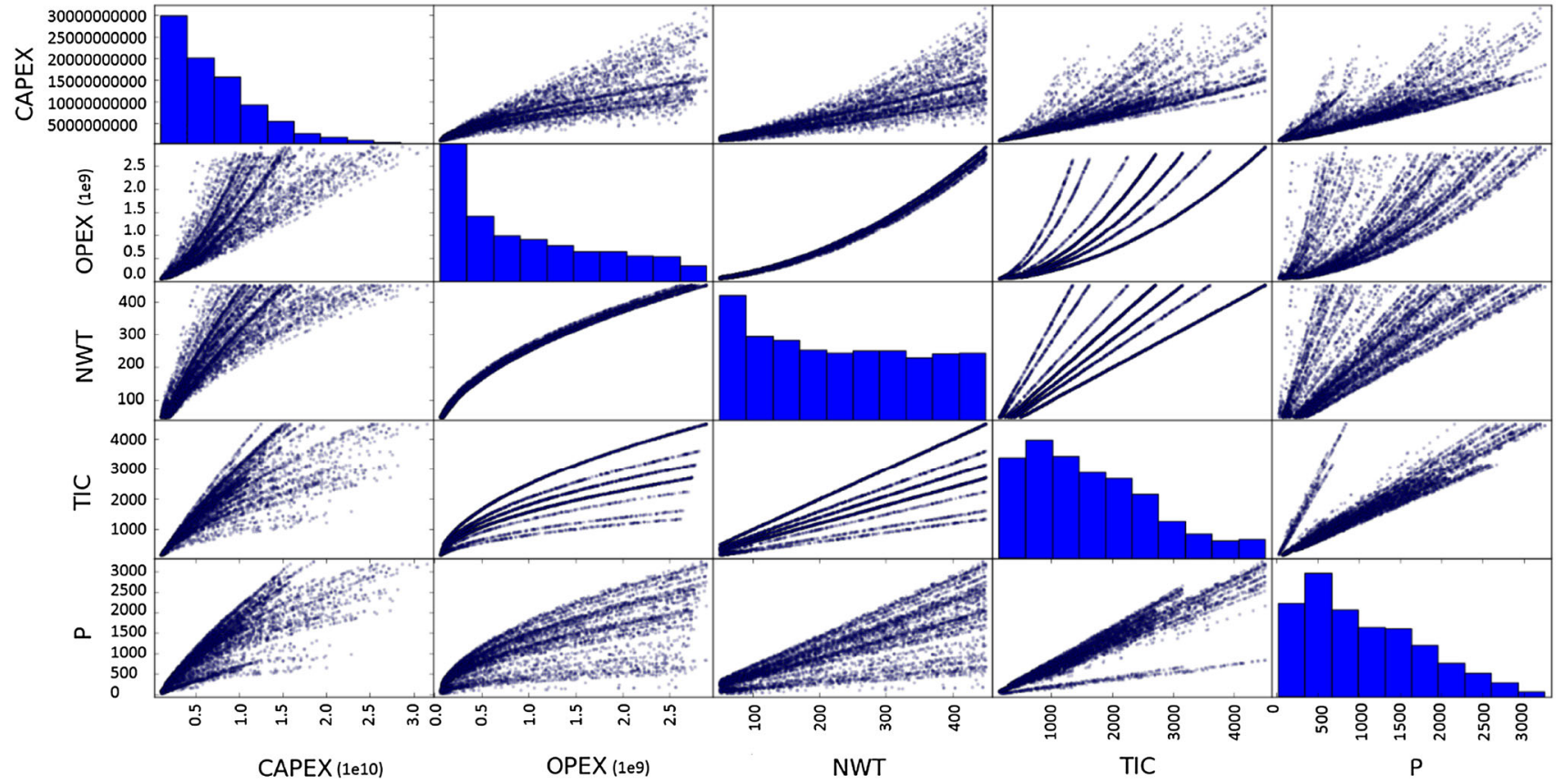

Fig. 9 Scatter plot matrix among CAPEX, OPEX, NWT, P, and TIC using NSGAIII

suggests to be compound into a single objective in the future, for simplicity. In addition, $C_{\mathrm{O} \& \mathrm{M}}$ and NWT also vary in harmony by following a parabolic trend. In the same figures, most of the discovered solutions live at the lower end of the range of $C_{\mathrm{P} \& \mathrm{~A}}$ and $C_{\mathrm{P} \& \mathrm{C}}$. This points out future research directions, so as to identify areas, where the performance remains constant.
In the histogram of $C_{\mathrm{O} \& \mathrm{M}}$, many points of the optimal revealed behaviour reside at the lower bound of the range of the objective. Consequently, this is also noted in the concentration of points in the CAPEX and OPEX. This was the easiest to discover relative to the other objectives. Because the shape of the trade-offs among $C_{\mathrm{P} \& \mathrm{~A}}, C_{\mathrm{P} \& \mathrm{C}}$, and $C_{\mathrm{I} \& \mathrm{C}}$ is similar and the same holds of the trends of the histograms, 


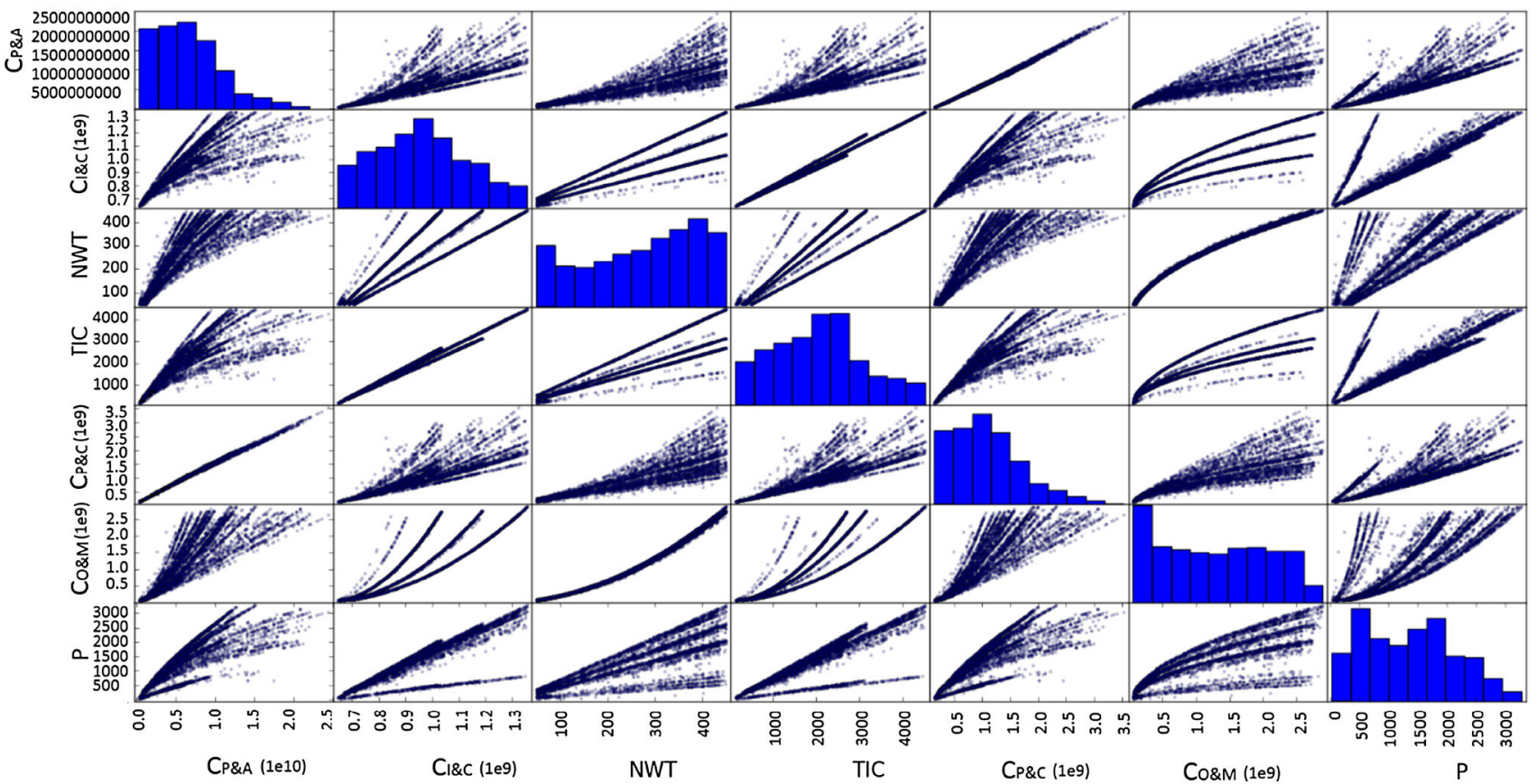

Fig. 10 Scatter plot matrix among the seven objectives, i.e., $C_{\mathrm{A} \& \mathrm{P}}, C_{\mathrm{P} \& \mathrm{C}}, C_{\mathrm{I} \& \mathrm{C}}, C_{\mathrm{O} \& \mathrm{M}}, \mathrm{NWT}, \mathrm{P}$, and TIC using SPEA2

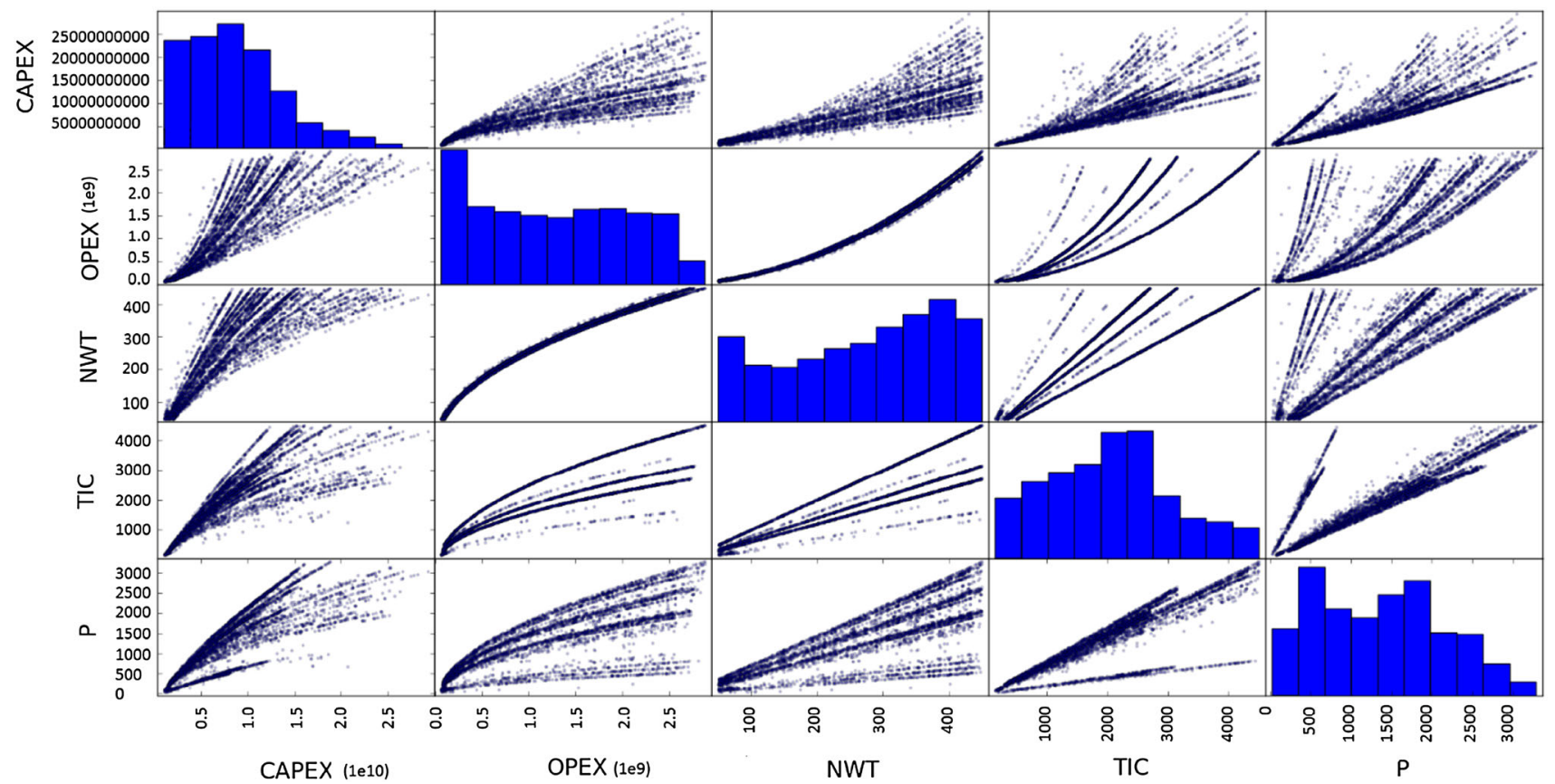

Fig. 11 Scatter plot matrix among CAPEX, OPEX, NWT, P, and TIC using SPEA2

it is sensible to consider the CAPEX objective in the future steps of the research (instead of all these three individual objectives).

In SPEA 2 and NSGAII results, the sparse dots at the end of each graph represent that the method (i.e., the search patterns employed by those algorithms) has not discovered a wide range of solutions in those areas.
Several results show a relative harmony between each other and some others show the conflicting performance between the objectives. Six offshore locations scored higher than $10 \%$ in the frequency graph, i.e., the Seagreen Alpha and Bravo (in Firth of Forth), Teesside C and D (in Dogger Bank), Rampion (Hastings), and the Celtic Array South West Potential development Area, which represent the Irish Sea 


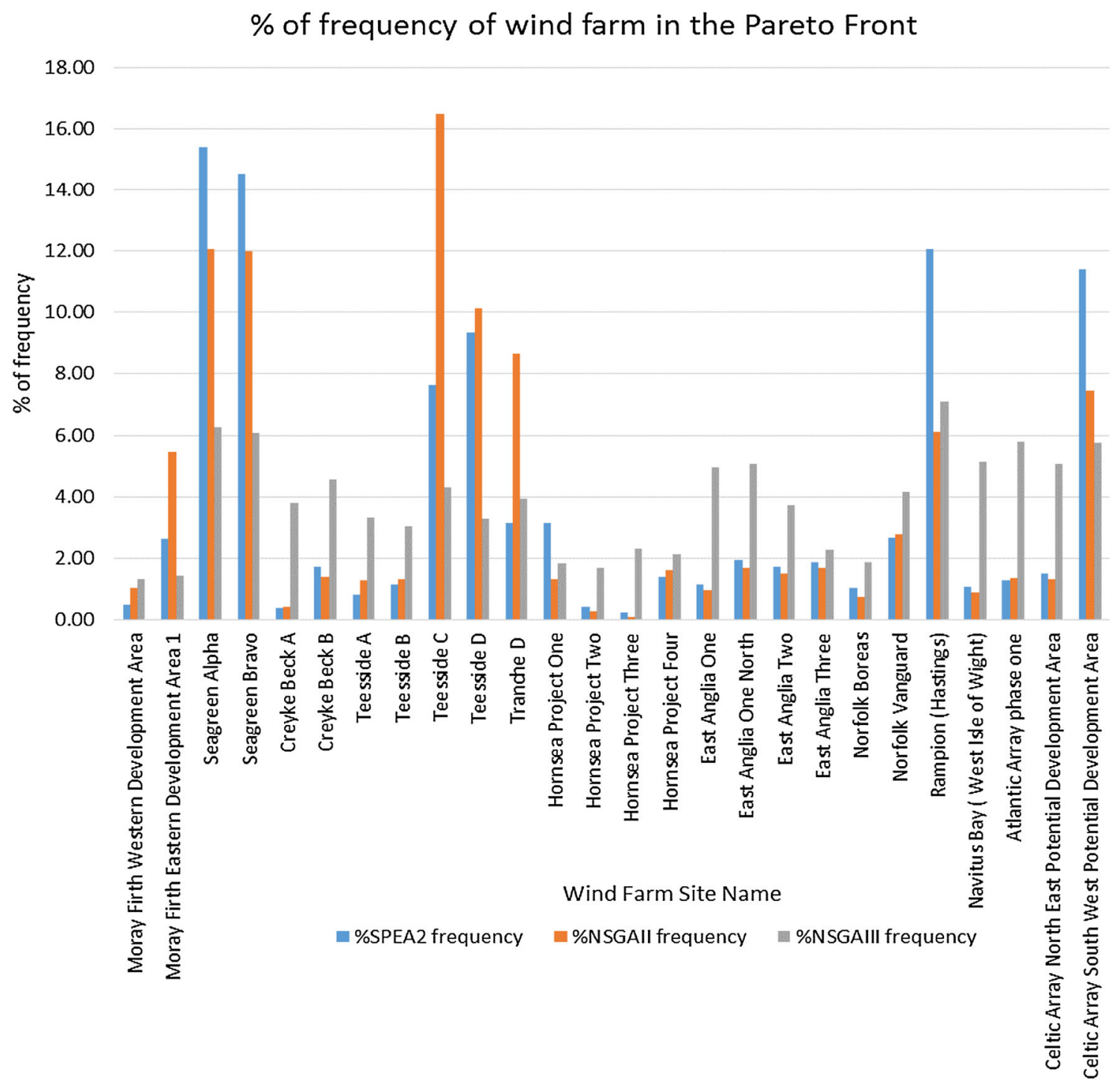

Fig. $12 \%$ of frequency of each site from the pareto front solutions from SPEA2, NSGAII, and NSGAIII

(Celtic Array). A frequency graph has been created in Fig. 12 to summarise and depict the $\%$ frequency of each offshore location that appears in the pareto front solutions. In general, the Firth of Forth, Dogger Bank, and Irish Sea (Celtic Array) zones reached the highest score for all optimisers.

The Teesside $\mathrm{C}$ scored first and it is closely followed by Seagreen Bravo when using NSGAII. The Seagreen Alpha in Firth of Forth seems to have the highest scores of all when using the SPEA2 algorithm, and thus, it is considered one of the best options for a wind farm project, as it was identified by all three optimisers. Finally, Seagreen Alpha was scored first for the NSGAIII. In general, the Hornsea Projects family has been found to be suitable in only a small amount of appearances in the pareto front.

The performance of the algorithms has shown that NSGAIII demonstrated its suitability in multi-objective problems as its results appear to be more uniform and clear because of its main design, compared to the other optimisers. Therefore, the trade-offs for certain pairs of objectives are more complete, wider, and richer, in terms of a number of points. In general, the patterns of the revealed trade-off are very clear and distinct for the results from NSGAIII with 12 divisions.

The non-dominated results demonstrate that employing MOO algorithms was a sensible choice, so as to complement the process of wind farm location selection. For example, both Moray Firth Western Development Area and Seagreen Alpha were found to be in the trade-off at least once by the optimisers. For the developer, this means that it is equally cost efficient to choose either location. However, the latter has appeared significantly more frequent than the former. The developer could accordingly allocate the development 


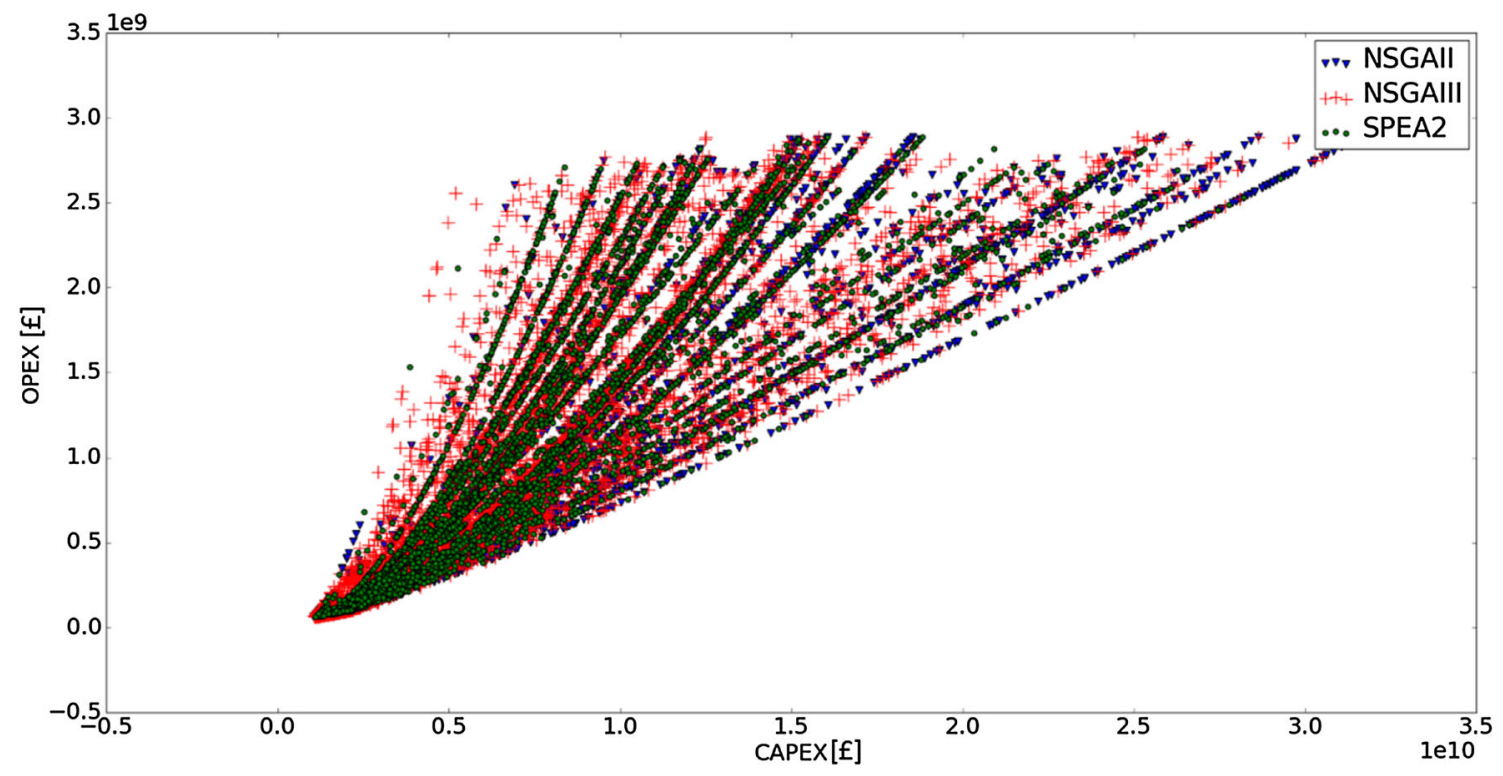

Fig. 13 Comparison of CAPEX versus OPEX using NSGAII, NSGAIII, and SPEA2

Table 4 Selected solution based on high frequency (from Fig. 12) for each algorithm

\begin{tabular}{llrrrr}
\hline Algorithm & Site name & Turbine type (MW) & NWT & TIC (MW) & $P(\mathrm{MW})$ \\
\hline \multirow{2}{*}{ SPEA 2 } & Seagreen Alpha & 10 & 148 & 1480 & 718.04 \\
& Seagreen Bravo & 6 & 308 & 1848 & 157.70 \\
& Rampion (Hastings) & 6 & 185 & 1110 & 475.86 \\
\multirow{2}{*}{ NSGA II } & Teesside C & 10 & 402 & 4020 & 2846.06 \\
& Seagreen Alpha & 3 & 449 & 1347 & 685.93 \\
& Seagreen Bravo & 6 & 117 & 702 & 536.49 \\
\multirow{3}{*}{ NSGA III } & Rampion (Hastings) & 8 & 261 & 2088 & 360.56 \\
& Seagreen Alpha & 10 & 293 & 2930 & 1994.90 \\
& Seagreen Bravo & 7 & 50 & 350 & 290.17 \\
\hline
\end{tabular}

budget in different development phases, as required. More specifically, the Seagreen Alpha provides many more optimum options that are equally efficient (involving the number and type of turbines in each solution) than the Moray Firth Western Development Area, which gives the flexibility to invest more money in the installation or the maintenance stage of the project.

An application has been submitted and consented for the Firth of Forth Seagreen Alpha and Bravo, which are at the first phase of the Round 3 Firth of Forth development according to 4COffshore (2017f), RYA (2017). Both Seagreen Alpha and Bravo faced some engineering and environmental problems and developed the project accordingly to accommodate such constraints that appeared in their offshore locations (4COffshore 2017f). Teesside C and D in Dogger Bank applications were submitted together by Forewind. Unfortunately, the projects have been cancelled according to 4COffshore (2017a, 2017b). Rampion (Hastings) is currently under construction according to 4COffshore (2017e). Finally, Celtic
Array South West Potential development Area was also cancelled (4COffshore 2014).

Probably, the six primary selected offshore locations have been either cancelled, consented or just submitted and only one of them is under construction, because other factors are also involved in the selection process. For example, the cancellation in all cases happened, because the Crown Estate asked the developers to revise all the terms of their agreement, while the project transitioned toward the development phase (4COffshore 2017e). Other reasons could also result in cancellation such as environmental problems, legal and procurement restrictions, etc.

By relating some of the most important techno-economic LCC factors to the physical aspects of each wind location (i.e., the wind speed, distance from the ports, and water depth), the wind turbine siz,e and the number of turbines, it is possible to discover a more cost-efficient solution. By comparing the outcomes of the three algorithms and suggesting the most suitable locations, useful insights are provided 
for both industrial and educational purposes in the wind sector for future investments.

In Fig. 13, the performance of each optimisation algorithm in CAPEX versus OPEX is shown. As expected, most of the solutions gather at the lower left end. NSGAII and SPEA2 discovered and followed certain trends for a particular wind turbine, as shown by the various legs in the figure. Because of the design of NSGAIII, the discovered solutions are more spread throughout the objective space.

Table 4 shows the top three locations discovered by each optimiser in terms of frequency in the Pareto Front from Fig. 12. The listed solutions were selected manually so as to demonstrate the conflicting nature of the objectives. The table numerically demonstrates the conflict among the objectives in the trade-off, for instance, comparing Seagreen Alpha and Seagreen Bravo using SPEA 2 algorithm, when the NWT increases then $\mathrm{P}$ decreases. In the results of the same algorithm, including Rampion (Hastings), when the NWT increases, TIC reduces (whereas previously, it increased). This demonstrates the conflicting nature of the results and non-linear relationships, which will be further investigated in the future.

From the obtained results, the average savings were calculated to assess the performance of the approach and the framework. An average savings formula was used (i.e., Average savings $=\frac{\text { Maximum cost-Average cost }}{\text { Maximum cost }}$ ) to calculate percentages for CAPEX and OPEX using NSGA II, NSGA III, and SPEA 2. NSGA II reached 77 and $66.7 \%$ savings for CAPEX and OPEX, respectively. NSGA III found 69.1 and $59.2 \%$ for CAPEX and OPEX, respectively. Finally, SPEA 2 shows 70.1 and $55.8 \%$ savings for CAPEX and OPEX, respectively. It appears that the optimisation approach can discover solutions with lower CAPEX deviation than OPEX. The high percentages were expected because of the large number of conflicting objectives which forces the optimisers to discover a great number of solutions in the Pareto Front.

\section{Conclusions}

This study successfully demonstrated by example the effectiveness of the newly developed optimisation process and delivered satisfactory outcomes for the most suitable and cost-efficient offshore wind farm Round 3 locations. A comparison has been presented among the three state-of-the-art algorithms (i.e., NSGA II, NSGA III, and SPEA 2), which were applied to a wind energy real-world case. The comparison and the useful outcomes on their performance have been illustrated and discussed. The optimum locations for a wind farm have been suggested by considering the significant input of the LCC analysis. Six sites were suggested (with the frequency of appearance higher than $10 \%$ in the parent front).
The results follow a relatively similar and consistent trend. The performance of the algorithms has shown that the NSGAIII demonstrated its suitability in multi-objective problems as its results appear to be more uniform and clear because of its design compared to the other optimisers.

The limitations of this work are related to the LCC calculations and the associated assumptions that had to be made in the development of the model. To get more accurate results, more precise data are required to validate and calibrate the LCC, which could refine the results of this work. Many data and assumptions taken for this study have been obtained and chosen from wind-related databases and crown estate reports, to reach the real-world values. However, research and surveys are important for every individual site to have more accurate inputs. Data acquisition is the hardest part as it is impossible for a developer to proceed without a project plan. Here, only one type of foundation was considered, the jacket structure. The impact of Net Present Value on the economic objectives (i.e., CAPEX and OPEX) has not been considered and will be further investigated in the future.

The revealed outcomes will have an important impact on a possible extension of the Round 3 zones in the future of the UK and will help decision makers for their next cost efficient investment move. The proposed framework could also be applied to other sectors to increase investment confidence and provide optimum solutions. For example, the installation of floating offshore wind and wave devices could be benefited by the framework, where the optimum locations can be suggested according to cost and operational aspects for each technological need.

Acknowledgements This work was supported by Grant EP/L016303/1 for Cranfield University, Centre for Doctoral Training in Renewable Energy Marine Structures (REMS) (http://www.rems-cdt.ac.uk/) from the UK Engineering and Physical Sciences Research Council (EPSRC).

Open Access This article is distributed under the terms of the Creative Commons Attribution 4.0 International License (http://creativecomm ons.org/licenses/by/4.0/), which permits unrestricted use, distribution, and reproduction in any medium, provided you give appropriate credit to the original author(s) and the source, provide a link to the Creative Commons license, and indicate if changes were made.

\section{References}

4COffshore Celtic Array South West Potential Development Area Offshore Wind Farm (2014) http://www.4coffshore.com/windfarms/ celtic-array-south-west-potential-development-area-united-king dom-uk1r.html

4COffshore Dogger Bank-Teesside C Offshore Wind Farm (2017a) http://www.4coffshore.com/windfarms/dogger-bank-teesside-cunited-kingdom-uk1h.html. Accessed 2017

4COffshore Dogger Bank-Teesside D Offshore Wind Farm (2017b) http://www.4coffshore.com/windfarms/dogger-bank-teesside-dunited-kingdom-uk1i.html. Accessed 2017 
4COffshore Global offshore wind farms database (2017c) http://www. 4coffshore.com/offshorewind/index.html?lat=50.668\&lon=-0. 275\&wfid=UK36. Accessed 2017

4COffshore Offshore Turbine Database (2017d) http://www. 4coffshore.com/windfarms/turbines.aspx. Accessed 2017

4COffshore Rampion Offshore Wind Farm (2017e) http://www. 4coffshore.com/windfarms/rampion-united-kingdom-uk36.html. Accessed 2017

4COffshore Seagreen Bravo Offshore Wind Farm (2017f) http://www. 4coffshore.com/windfarms/seagreen-bravo-united-kingdom-uk 1a.html. Accessed 2017

Adinolfi G, Graditi G, Siano P, Piccolo A (2015) Multiobjective optimal design of photovoltaic synchronous boost converters assessing efficiency, reliability, and cost savings. IEEE Trans Ind Inform 11:1038-1048. doi:10.1109/TII.2015.2462805

Angelakoglou K, Botsaris PN, Gaidajis G (2014) Issues regarding wind turbines positioning: a benchmark study with the application of the life cycle assessment approach. Sustain Energy Technol Assess 5:7-18

BEC CREW (2015) Here's what you need to know about the new Paris climate deal. http://www.sciencealert.com/here-s-whatyou-need-to-know-about-the-climate-deal-from-paris. Accessed 2017

Branke J, Deb K, Miettinen K, Slowiński R (2008) Multiobjective optimization: interactive and evolutionary approaches. Springer, Berlin, Heidelberg

Brownlee J (2011) Clever algorithms nature-inspired programming recipes. lulu.com http://dl.acm.org/citation.cfm?id=1983645

Cagan J, Shimada K, Yin S (2002) A survey of computational approaches to three-dimensional layout problems. Comput Aided Des 34:597-611. doi:10.1016/S0010-4485(01)00109-9

Chiang T-C (2014) nsga3cpp: a C++ implementation of NSGA-III. http://web.ntnu.edu.tw/ tcchiang/publications/nsga3cpp/nsga3cp p-installation.htm. Accessed 2017

Cradden L, Kalogeri C, Barrios IM, Galanis G, Ingram D, Kallos G (2016) Multi-criteria site selection for offshore renewable energy platforms. Renew Energy 87(Part 1):791-806. doi:10. 1016/j.renene.2015.10.035

Deb K (2001) Multi-objective optimization using evolutionary algorithms. Wiley, New York, US

Deb K, Agrawal RB (1994) Simulated binary crossover for continuous search space. Complex Syst 9:1-15

Deb K, Jain H (2014) An evolutionary many-objective optimization algorithm using reference-point-based nondominated sorting approach, part I: Solving problems with box constraints. IEEE Trans Evol Comput 18:577-601

Department of Energy and Climate Change (2009) UK ports for the offshore wind industry: time to act. http://webarchive.natio nalarchives.gov.uk/+/http:/www.berr.gov.uk/files/file49871.pdf. Accessed 2017

Department of Energy and Climate Change (2011) UK renewable energy roadmap. https://www.gov.uk/government/uploads/ system/uploads/attachment_data/file/48128/2167-uk-renewableenergy-roadmap.pdf. Accessed 2017

Dicorato M, Forte G, Pisani M, Trovato M (2011) Guidelines for assessment of investment cost for offshore wind generation. Renew Energy 36:2043-2051. doi:10.1016/j.renene.2011.01.003

Elkinton CN, Manwell JF, McGowan JG (2008) Algorithms for offshore wind farm layout optimization. Wind Eng 32:67-84

Espinosa IA (2014) Life cycle costing of offshore wind turbines. MSc Thesis. Cranfield University, Cranfield, UK

European Observation Network for Territorial Development and Cohesion (2011) Inspire policy making by territorial evidence. http://www.espon.eu/main/Menu_Publications/Menu_MapsOf TheMonth/map1101.html. Accessed 2017
Fuller SK, Petersen SR (1996) Life-cycle costing manual for the federal energy management program, 1995 Edition. NIST handbook 135

González JS, Gonzalez Rodriguez AG, Mora JC, Santos JR, Payan MB (2010) Optimization of wind farm turbines layout using an evolutive algorithm. Renew Energy 35:1671-1681. doi:10.1016/ j.renene.2010.01.010

Graditi G, Adinolfi G, Tina GM (2014) Photovoltaic optimizer boost converters: temperature influence and electro-thermal design. Appl Energy 115:140-150. doi:10.1016/j.apenergy.2013.10.031

Hadka D (2015) Platypus. http://platypus.readthedocs.io/en/latest/ experimenter.html\#comparing-algorithms-visually. Accessed 2017

HM Government (2013) Offshore wind industrial strategy business and government action. https://www.gov.uk/government/uploads/ system/uploads/attachment_data/file/243987/bis-13-1092-offsho re-windindustrial-strategy.pdf. Accessed 19 July 2017

Ippolito MG, Di Silvestre ML, Riva Sanseverino E, Zizzo G, Graditi G (2014) Multi-objective optimized management of electrical energy storage systems in an islanded network with renewable energy sources under different design scenarios. Energy 64:648662. doi:10.1016/j.energy.2013.11.065

Jain H, Deb K (2014) An evolutionary many-objective optimization algorithm using reference-point based nondominated sorting approach, part II: handling constraints and extending to an adaptive approach. IEEE Trans Evol Comput 18:602-622

Jones DF, Wall G (2015) An extended goal programming model for site selection in the offshore wind farm sector. Ann Oper Res. doi:10. 1007/s10479-015-1828-2

Kamjoo A, Maheri A, Dizqah AM, Putrus GA (2016) Multi-objective design under uncertainties of hybrid renewable energy system using NSGA-II and chance constrained programming. Int J Electr Power Energy Syst 74:187-194. doi:10.1016/j.ijepes.2015.07.007

Karimi M, Hall M, Buckham B, Crawford C (2017) A multi-objective design optimization approach for floating offshore wind turbine support structures. J Ocean Eng Mar Energy 3:69-87. doi:10.1007/ s40722-016-0072-4

Kolios A, Collu M, Chahardehi A, Brennan F, Patel M (2010) A multicriteria decision making method to compare support structures for offshore wind turbines. In: European Wind Energy Conference, Warsaw

Kolios A, Mytilinou V, Lozano-Minguez E, Salonitis K (2016) A comparative study of multiple-criteria decision-making methods under stochastic inputs. Energies. doi:10.3390/en9070566

Kolios AJ, Rodriguez-Tsouroukdissian A, Salonitis K (2014) Multicriteria decision analysis of offshore wind turbines support structures under stochastic inputs. Ships Offshore Struct 11(1):38-49

Laura C-S, Vicente D-C (2014) Life-cycle cost analysis of floating offshore wind farms. Renew Energy 66:41-48. doi:10.1016/j.renene. 2013.12.002

Lin S-Y, Chen J-F (2013) Distributed optimal power flow for smart grid transmission system with renewable energy sources. Energy 56:184-192. doi:10.1016/j.energy.2013.04.011

Lozano-Minguez E, Kolios AJ, Brennan FP (2011) Multi-criteria assessment of offshore wind turbine support structures. Renew Energy 36:2831-2837. doi:10.1016/j.renene.2011.04.020

Marine Traffic Marine traffic. http://www.marinetraffic.com. Accessed 2017

Martin H, Spano G, Küster JF, Collu M, Kolios AJ (2013) Application and extension of the TOPSIS method for the assessment of floating offshore wind turbine spport structures. Ships Offshore Struct 8:477-487. doi:10.1080/17445302.2012.718957

Martínez E, Sanz F, Pellegrini S, Jiménez E, Blanco J (2009) Life cycle assessment of a multi-megawatt wind turbine. Renew Energy 34:667-673. doi:10.1016/j.renene.2008.05.020 
Meza JLC, Yildirim MB, Masud AS (2009) A multiobjective evolutionary programming algorithm and its applications to power generation expansion planning. IEEE Trans Syst Man Cybern Part A Syst Hum 39(5):1086-1096

Mirjafari M, Balog RS (2012) Multi-objective optimization of the energy capture and boost inductor mass in a module-integrated converter (MIC) photovoltaic energy system. In: Applied power electronics conference and exposition (APEC), 2012 twentyseventh annual IEEE, Orlando, US, pp 2002-2007. doi:10.1109/ APEC.2012.6166097

Momoh JA, Reddy SS (2014) Review of optimization techniques for renewable energy resources. In: IEEE symposium on power electronics and machines for wind and water applications, pp 1-8. doi:10.1109/PEMWA.2014.6912225

Myhr A, Bjerkseter C, Ågotnes A, Nygaard TA (2014) Levelised cost of energy for offshore floating wind turbines in a life cycle perspective. Renew Energy 66:714-728. doi:10.1016/j.renene.2014. 01.017

Mytilinou V, Kolios AJ, Di Lorenzo G (2015) A comparative multidisciplinary policy review in wind energy developments in Europe. Int J Sustain Energy 1-21: doi:10.1080/14786451.2015.1100194

Nalianda DK (2012) Impact of environmental taxation policies on civil aviation-a techno-economic environmental risk assessment. PhD Dissertation, Cranfield University, Cranfield, UK

Nordahl M (2011) The development of a life cycle cost model for an offshore wind farm. MSc Thesis, Chalmers University of Technology, Göteborg, Sweden

Papatheou E, Dervilis N, Maguire AE, Antoniadou I, Worden K (2015) A performance monitoring approach for the novel Lillgrund offshore wind farm. IEEE Trans Ind Electron 62(10):6636-6644

Perkgoz C, Sakawa KKM, Kato K, Katagiri H (2005) An interactive fuzzy satisficing method for multiobjective stochastic integer programming problems through a probability maximization model. Asia Pac Manag Rev 10:29-35

QGIS A Free and Open Source Geographic Information System. http:// www.qgis.org/en/site/index.html. Accessed 2017

Renewables First What are the main project risks for wind power? (2017) https://www.renewablesfirst.co.uk/windpower/windpower -learning-centre/what-are-the-main-project-risks-for-wind-pow er/. Accessed 2017

RYA Round 3 wind farms. http://www.rya.org.uk/knowledge-advice/ offshore-renewables/Pages/round-3-wind-farms.aspx. Accessed 2017

Saavedra-Moreno B, Salcedo-Sanz S, Paniagua-Tineo A, Prieto L, Portilla-Figueras A (2011) Seeding evolutionary algorithms with heuristics for optimal wind turbines positioning in wind farms. Renew Energy 36:2838-2844. doi:10.1016/j.renene.2011.04.018

Sakawa M, Kato K, Katagiri H (2004) An interactive fuzzy satisficing method for multiobjective linear programming problems with random variable coefficients through a probability maximization model. Fuzzy Sets Syst 146:205-220. doi:10.1016/j.fss.2004.04. 003
Sakawa M, Matsui T, Katagiri H (2013) An interactive fuzzy satisficing method for random fuzzy multiobjective integer programming problems through probability maximization with possibility. Fuzzy Inf Eng 5:335-350. doi:10.1007/s12543-013-0146-0

Shafiee M, Brennan F, Espinosa IA (2015) Whole life-cycle costing of large-scale offshore wind farms. Paper presented at the Conference: European Wind Energy Association (EWEA) Paris, France

Stewart T et al (2008) Real-world applications of multiobjective optimization. Multiobjective Optim Interact Evol Approaches 285-327: doi:10.1007/978-3-540-88908-3_11

The Crown Estate (2010a) The Crown Estate announces Round 3 offshore wind development partners. http://www.thecrownestate.co. uk/news-and-media/news/2010/the-crown-estate-announces-rou nd-3-offshore-wind-development-partners/. Accessed 2017

The Crown Estate (2010b) Round 3 zone appraisal and planning. A strategic approach to zone design, project identification and consent. https://www.thecrownestate.co.uk/media/5702/ei-km-inpc-method-052010-round-3-zone-appraisal-and-planning.pdf. Accessed 2017

The Crown Estate (2013) Round 3 offshore wind site selection at national and project levels. https://www.thecrownestate.co.uk/me ia/5644/ei-km-in-pc-planning-062013-round-3-offshore-windsite-selection-at-national-and-project-levels.pdf

The Crown Estate (2017) A guide to an offshore wind farm. The Crown Estate. https://www.thecrownestate.co.uk/media/5408/eikm-in-sc-supply-012010-a-guide-to-an-offshore-wind-farm.pdf. Accessed 2017

UK Ports Directory Ports The Comprehensive Guide to the UK's commercial ports. http://uk-ports.org/. Accessed 2017

Wan C, Wang J, Yang G, Gu H, Zhang X (2012) Wind farm micrositing by Gaussian particle swarm optimization with local search strategy. Renew Energy 48:276-286. doi:10.1016/j.renene.2012. 04.052

Wind energy The facts (2017) Development and investment costs of offshore wind power. http://www.wind-energy-the-facts.org/dev elopment-and-investment-costs-of-offshore-wind-power.html. Accessed 2017

Wolpert DH, Macready WG (1997) No free lunch theorems for optimization. IEEE Trans Evol Comput 1:67-82. doi:10.1109/4235. 585893

Yan G (2009) Research on green suppliers' evaluation based on AHP \& genetic algorithm. In: International conference on signal processing systems, pp 615-619. doi:10.1109/ICSPS.2009.92

Yeh W-C, Chuang M-C (2011) Using multi-objective genetic algorithm for partner selection in green supply chain problems. Expert Syst Appl 38:4244-4253. doi:10.1016/j.eswa.2010.09.091

Yuan Y, Xu H, Wang B (2014) An improved NSGA-III procedure for evolutionary many-objective optimization. In: Proceedings of the 2014 annual conference on genetic and evolutionary computation, ACM, pp 661-668

Zitzler E, Laumanns M, Thiele L (2001) SPEA2: improving the strength Pareto evolutionary algorithm. Eurogen, Athens 103:95-100 